\title{
Strong Convergence of a General Iterative Algorithm for Mixed Equilibrium, Variational Inequality and Common Fixed Points Problems
}

\author{
Tanakit Thianwan ${ }^{1,2}$ \\ ${ }^{1}$ Department of Mathematics, School of Science, University of Phayao, Phayao, Thailand \\ ${ }^{2}$ Centre of Excellence in Mathematics, CHE, Si Ayutthaya Rd., Bangkok, 10400, Thailand \\ Email: tanakit.th@up.ac.th
}

Received September 14, 2012; revised November 1, 2012; accepted November 20, 2012

\begin{abstract}
The aim of this paper, is to introduce and study a general iterative algorithm concerning the new mappings which the sequences generated by our proposed scheme converge strongly to a common element of the set of solutions of a mixed equilibrium problem, the set of common fixed points of a finite family of nonexpansive mappings and the set of solutions of the variational inequality for a relaxed cocoercive mapping in a real Hilbert space. In addition, we obtain some applications by using this result. The results obtained in this paper generalize and refine some known results in the current literature.
\end{abstract}

Keywords: Nonexpansive Mapping; Mixed Equilibrium Problem; Variational Inequality; Common Fixed Points; Strong Convergence

\section{Introduction}

Let $H$ be a real Hilbert space, whose inner product and norm are denoted by $\langle\cdot \cdot \cdot\rangle$ and $\|\cdot\|$, respectively. Let $C$ be a nonempty closed convex subset of $H$. A mapping $T: C \rightarrow C$ is called nonexpansive if $\|T x-T y\| \leq\|x-y\|$ for all $x, y \in C$. We denote by

Fix $(T)=\{x \in H: T x=x\}$ the set of fixed points of $T$. A linear bounded operator $A$ is strongly positive if there is a constant $\bar{\gamma}>0$ with the property $\langle A x, x\rangle \geq \bar{\gamma}\|x\|^{2}$ for all $x \in H$. A mapping $f: H \rightarrow H$ is said to be a contraction if there exists a coefficient $\alpha(0<\alpha<1)$ such that $\|f(x)-f(y)\| \leq \alpha\|x-y\|$ for all $x, y \in H$. Let $P_{C}$ be the nearest point projection of $H$ onto the convex subset $C$ (i.e., for $x \in H, P_{C}$ is the only point in $C$ such that $\left\|x-P_{C} x\right\|=\inf \{\|x-y\|: y \in C\}$. It is known that projection operator $P_{C}$ is nonexpansive. It is also known that $P_{C}$ satisfies $\left\langle x-y, P_{C} x-P_{C} y\right\rangle \geq\left\|P_{C} x-P_{C} y\right\|^{2}$ for $x, y \in H$. The following characterizes the projection $P_{C}$ Given $z \in H$ and $u \in C$. Then $u=P_{C} z$ if and only if there holds the relations:

$$
\langle z-u, u-v\rangle \geq 0
$$

for all $v \in C$ (see [1]). Moreover, $P_{C} x$ is characterized by the properties: $P_{C} x \in C$ and $\left\langle x-P_{C} x, P_{C} x-y\right\rangle \geq 0$

${ }^{*}$ This research is (partially) supported by the Centre of Excellence in Mathematics, the Commission on Higher Education, Thailand. for all $y \in C$. Let $B: C \rightarrow H$ be a nonlinear map. The classical variational inequality problem, denoted by $\operatorname{VI}(C, B)$ is to find $u \in C$ such that

$$
\langle B u, v-u\rangle \geq 0
$$

for all $v \in C$. One can see that the variational inequality problem (1.2) is equivalent to the following fixed point problem: the element $u \in C$ is a solution of the variational inequality (1.2) if and only if $u \in C$ satisfies the relation $u=P_{C}(I-\lambda B) u$, where $\lambda>0$ is a constant. This alternative equivalent formulation has played a significant role in the studies of the variational inequalities and related optimization problems.

Iterative methods for nonexpansive mappings have recently been applied to solve convex minimization problems; see, for example, [2-6] and the references therein. A typical problem is that of minimizing a quadratic function over the set of the fixed points of a nonexpansive mapping on a real Hilbert space $H$ :

$$
\min _{x \in \operatorname{Fix}(s)} \frac{1}{2}\langle A x, x\rangle-\langle x, b\rangle,
$$

where $A$ is a linear bounded operator and $b$ is a given point in $H$. In [5] (see also [6]), it is proved that the sequence $\left\{x_{n}\right\}$ defined by the iterative method below, with the initial guess $x_{0} \in H$ chosen arbitrarily,

$$
x_{n+1}=\alpha_{n} b+\left(I-\alpha_{n} A\right) S x_{n}, n \geq 0,
$$


converges strongly to the unique solution of the minimization problem (1.3) provided the sequence $\left\{\alpha_{n}\right\}$ satisfies certain conditions. In 2006, Marino and Xu (see [3]) considered the following viscosity iterative method which was first introduced by Moudafi (see [7]):

$$
x_{n+1}=\alpha_{n} \gamma f\left(x_{n}\right)+\left(I-\alpha_{n} A\right) S x_{n}, n \geq 0
$$

They proved that the sequence $\left\{x_{n}\right\}$ generated by iterative scheme (1.4) converges strongly to the unique solution of the variational inequality

$\left\langle(A-\gamma f) x^{*}, x-x^{*}\right\rangle \geq 0, \quad x \in C$ which is the optimality condition for the minimization problem

$$
\min _{x \in \operatorname{Fix}(s)} \frac{1}{2}\langle A x, x\rangle-h(x),
$$

where $h$ is a potential function for $\gamma f$ (i.e., $h^{\prime}(x)=\gamma f(x)$ for $\left.x \in H\right)$.

For finding a common element of the set of fixed points of a nonexpansive mapping and the set of solutions of the variational inequality for $\alpha$-cocoercive mapping, Takahashi and Toyoda (see [11]) introduced the following iterative process: $x_{0} \in C$,

$$
x_{n+1}=\alpha_{n} x_{n}+\left(1-\alpha_{n}\right) S P_{C}\left(x_{n}-\lambda_{n} B x_{n}\right), n \geq 0,
$$

where $B$ is $\alpha$-cocoercive, $\left\{\alpha_{n}\right\} \subset(0,1)$, and $\left\{\lambda_{n}\right\} \subset(0,2 \alpha)$. They showed that, if $\operatorname{Fix}(S) \cap V I(C, B)$ is nonempty, then the sequence $\left\{x_{n}\right\}$ generated by (1.5) converges weakly to some $z \in \operatorname{Fix}(S) \cap V I(C, B)$. In 2005, Iiduka and Takahashi (see [12]) introduced the following iterative process:

$$
x_{n+1}=\alpha_{n} u+\left(1-\alpha_{n}\right) S P_{C}\left(x_{n}-\lambda_{n} B x_{n}\right), n \geq 0,
$$

where $u \in C,\left\{\alpha_{n}\right\} \subset(0,1)$ and $\left\{x_{n}\right\} \subset(0,2 \alpha)$. They proved that under certain appropriate conditions imposed on $\left\{\alpha_{n}\right\}$ and $\left\{\lambda_{n}\right\}$, the sequence $\left\{x_{n}\right\}$ generated by (1.6) converges strongly to $z \in \operatorname{Fix}(S) \cap V I(C, B)$. In 2009, Qin, Kang and Shang, [13] introduced the following iterative algorithm given by $x_{1} \in C$,

$$
x_{n+1}=\alpha_{n} \gamma f\left(x_{n}\right)+\beta_{n} x_{n}+\left(\left(1-\beta_{n}\right) I-\alpha_{n} A\right) P_{C} S x_{n},
$$$$
n \geq 1 \text {, }
$$

where $C \pm C \subset C, T: C \rightarrow H$ a $k$-strict pseudo-contraction for some $0 \leq k<1, \quad S: C \rightarrow H$ defined by $S x=k x+(1-k) T x, \quad A$ is a strongly positive linear bounded self-adjoint operator and $f$ is a contraction. They proved that the sequence $\left\{x_{n}\right\}$ generated by the iterative algorithm (1.7) converges strongly to a fixed point of $T$, which solves a variational inequality related to the linear operator $A$.

Let $\varphi: C \rightarrow \mathbb{R} \cup\{+\infty\}$ be a proper extended realvalued function and $F$ be a bifunction from $C \times C$ to $\mathbb{R}$, where $\mathbb{R}$ is the set of real numbers. Ceng and Yao [14] considered the following mixed equilibrium prob- lem: Find $x \in C$ such that

$$
F(x, y)+\varphi(y) \geq \varphi(x)
$$

for all $y \in C$. The set of solutions of (1.8) is denoted by $\operatorname{MEP}(F, \varphi)$, i.e.,

$$
\operatorname{MEP}(F, \varphi)=\{x \in C: F(x, y)+\varphi(y) \geq \varphi(x), \forall y \in C\} .
$$

It is easy to see that $x$ is a solution of problem (1.8) implies that $x \in \operatorname{dom} \varphi=\{x \in C: \varphi(x)<+\infty\}$. Moreover, Ceng and Yao [14] introduced an iterative scheme for finding a common element of the set of solutions of problem (1.8) and the set of common fixed points of a family of finitely nonexpansive mappings in a Hilbert space and obtained a strong convergence theorem. If $\varphi=0$, then the mixed equilibrium problem (1.8) becomes the following equilibrium problem:

$$
F(x, y) \geq 0
$$

for all $y \in C$. The set of solutions of (1.9) is denoted by $E P(F)$, i.e.,

$$
E P(F)=\{x \in C: F(x, y) \geq 0, \forall y \in C\} .
$$

Given a mapping $T: C \rightarrow H$, let $\varphi=0$ and $F(x, y)=\langle T x, y-x\rangle$ for all $x, y \in C$. Then, $z \in \operatorname{MEP}(F, \varphi)$ if and only if $\langle T z, y-z\rangle \geq 0$ for all $y \in C$, i.e., $z$ is a solution of the variational inequality. Equilibrium problems have been studied extensively; see, for instance, [15,16]. The mixed equilibrium problem (1.8) is very general in the sense that it includes, as special cases, optimization problems, variational inequalities, minimax problems, Nash equilibrium problem in noncooperative games and others; see for instance, [14,16-19].

Combettes and Hirstoaga (see [15]) introduced an iterative scheme for finding the best approximation to the initial data when $\operatorname{EP}(F)$ is nonempty and proved a strong convergence theorem. In 2007, S. Takahashi and W. Takahashi (see [20]) introduced an iterative scheme using the viscosity approximation method for finding a common element of the set of solutions of equilibrium problem (1.9) and the set of fixed points of a nonexpansive nonself-mapping in a Hilbert space. The scheme is defined as follows: $x_{1} \in H$,

$$
\begin{cases}F\left(y_{n}, u\right)+\frac{1}{r_{n}}\left\langle u-y_{n}, y_{n}-x_{n}\right\rangle \geq 0, & \forall u \in C, \\ x_{n+1}=\alpha_{n} f\left(x_{n}\right)+\left(1-\alpha_{n}\right) S y_{n}, & n \geq 1 .\end{cases}
$$

They proved that under certain appropriate conditions imposed on $\left\{\alpha_{n}\right\}$ and $\left\{r_{n}\right\}$, the sequences $\left\{x_{n}\right\}$ and $\left\{y_{n}\right\}$ generated by (1.10) converge strongly to $z \in \operatorname{Fix}(S) \cap E P(F)$, where $z=P_{\operatorname{Fix}(S) \cap E P(F)} f(z)$. In the same year, Shang et al. (see [21]) introduced the following iterative scheme: $x_{1} \in H$, 


$$
\begin{cases}F\left(y_{n}, u\right)+\frac{1}{r_{n}}\left\langle u-y_{n}, y_{n}-x_{n}\right\rangle \geq 0, & \forall u \in C, \\ x_{n+1}=\alpha_{n} \gamma f\left(x_{n}\right)+\left(1-\alpha_{n} A\right) S y_{n}, & n \geq 1 .\end{cases}
$$

for finding a common element of the set of solutions of equilibrium problem (1.9) and the set of fixed points of a nonexpansive nonself-mapping in a Hilbert space. They proved that under some sufficient suitable conditions, the sequences $\left\{x_{n}\right\}$ and $\left\{y_{n}\right\}$ generated by (1.11) converge strongly to

$$
q \in \operatorname{Fix}(S) \cap E P(F),
$$

where

$$
q=P_{\mathrm{Fix}(S) \cap E P(F)}(\gamma f+(I-A)) q,
$$

which is the unique solution of the variational inequality

$$
\langle(\gamma f-A) q, p-q\rangle \leq 0
$$

for all $p \in \operatorname{Fix}(S) \cap E P(F)$.

Let $T_{i}: C \rightarrow C$, where $i=1,2, \cdots, N$, be a finite family of nonexpansive mappings. Finding an optimal point in the intersection $\cap_{i=1}^{N} \operatorname{Fix}\left(T_{i}\right)$ of the fixed points set of a finite family of nonexpansive mappings is a problem of interest in various branches of sciences; see [22-27] and also see [28] for solving the variational problems defined on the set of common fixed points of finitely many nonexpansive mappings. Atsushiba and Takahashi (see [29]), defined the mappings

$$
\begin{aligned}
& U_{n, 0}=I, \\
& U_{n, 1}=\lambda_{n, 1} T_{1} U_{n, 0}+\left(1-\lambda_{n, 1}\right) I, \\
& U_{n, 2}=\lambda_{n, 2} T_{2} U_{n, 1}+\left(1-\lambda_{n, 2}\right) I, \\
& \vdots \\
& U_{n, N-1}=\lambda_{n, N-1} T_{N-1} U_{n, N-2}+\left(1-\lambda_{n, N-1}\right) I, \\
& W_{n}=U_{n, N}=\lambda_{n, N} T_{N} U_{n, N-1}+\left(1-\lambda_{n, N}\right) I,
\end{aligned}
$$

where $\left\{\lambda_{n, 1}\right\},\left\{\lambda_{n, 2}\right\}, \cdots,\left\{\lambda_{n, N}\right\} \subset(0,1]$. Such a mapping $W_{n}$ is called the $W$-mapping generated by $T_{1}, T_{2}, \cdots, T_{N}$ and $\left\{\lambda_{n, 1}\right\},\left\{\lambda_{n, 2}\right\}, \cdots,\left\{\lambda_{n, N}\right\}$. The concept of $W$-mappings was introduced in [30-33]. In 2008, Qin et al. (see [34]) introduced and studied the following iterative process: $x_{1} \in H$,

$$
\begin{cases}F\left(y_{n}, \eta\right)+\frac{1}{r_{n}}\left\langle\eta-y_{n}, y_{n}-x_{n}\right\rangle \geq 0, & \forall \eta \in C, \\ x_{n+1}=\alpha_{n} \gamma f\left(W_{n} x_{n}\right)+\left(I-\alpha_{n} A\right) W_{n} P_{C}\left(I-s_{n} B\right) y_{n}, & n \geq 1,\end{cases}
$$

where $W_{n}$ is defined by (1.12), $A$ is a strongly linear bounded operator and $B$ is $\mu$-Lipschitzian, relaxed $(u, v)$-cocoercive mapping of $C$ into $H$. They proved that the sequences $\left\{x_{n}\right\}$ and $\left\{y_{n}\right\}$ generated by the iterative scheme (1.13) converge strongly to

$$
q \in \cap_{i=1}^{N} \operatorname{Fix}\left(T_{i}\right) \cap E P(F) \cap V I(C, B),
$$

where

$$
q=P_{\wedge_{i=1}^{N} \operatorname{Fix}\left(T_{i}\right) \cap E P(F) \cap V I(C, B)}(\gamma f+(I-A)) q,
$$

which is the unique solution of the variational inequality

$$
\langle(\gamma f-A) q, p-q\rangle \leq 0
$$

for all

$$
p \in \cap_{i=1}^{N} \operatorname{Fix}\left(T_{i}\right) \cap E P(F) \cap V I(C, B) .
$$

In the same year, Colao et al. (see [35]) introduced a new iterative scheme: $x_{1} \in H$,

$$
\begin{cases}F\left(y_{n}, u\right)+\frac{1}{r_{n}}\left\langle u-y_{n}, y_{n}-x_{n}\right\rangle \geq 0, & \forall u \in H, \\ x_{n+1}=\alpha_{n} \gamma f\left(x_{n}\right)+\beta x_{n}+\left((1-\beta) I-\alpha_{n} A\right) W_{n} y_{n}, & n \geq 1\end{cases}
$$

for approximating a common element of the set of solutions of equilibrium problem (1.9) and the set of common fixed points of a finite family of nonexpansive mappings and obtained a strong convergence theorem in a Hilbert space. In 2009, Yao et al. (see [36]) studied similar scheme as follows: $x_{1} \in H$,

$$
\begin{cases}F\left(y_{n}, u\right)+\frac{1}{r_{n}}\left\langle u-y_{n}, y_{n}-x_{n}\right\rangle \geq 0, & \forall u \in H, \\ x_{n+1}=\alpha_{n} \gamma f\left(x_{n}\right)+\beta_{n} x_{n}+\left(\left(1-\beta_{n}\right) I-\alpha_{n} A\right) W_{n} y_{n}, & n \geq 1\end{cases}
$$

where $\gamma>0,\left\{\alpha_{n}\right\},\left\{\beta_{n}\right\} \subset(0,1),\left\{r_{n}\right\} \subset(0, \infty)$ and $W_{n}$ is the $W$-mapping defined by (1.12). They proved that under certain appropriate conditions imposed on $\left\{\alpha_{n}\right\},\left\{\beta_{n}\right\},\left\{r_{n}\right\}$ and $\left\{\lambda_{n, i}\right\} \quad(\forall i=1,2, \cdots, N)$, the sequences $\left\{x_{n}\right\}$ and $\left\{y_{n}\right\}$ generated by (1.15) converge strongly to 


$$
x^{*} \in \cap_{i=1}^{N} \operatorname{Fix}\left(T_{i}\right) \cap E P(F),
$$

where

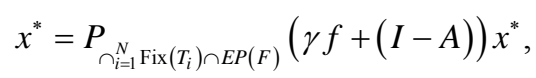

which is the unique solution of the variational inequality $\left\langle(\gamma f-A) x^{*}, x-x^{*}\right\rangle \leq 0$ for all $x \in \cap_{i=1}^{N} \operatorname{Fix}\left(T_{i}\right) \cap E P(F)$.

If $\beta_{n} \equiv \beta$ for some $\beta \in(0,1)$, then (1.15) reduces to the iterative scheme (1.14). Very recently, Kangtunyakarn and Suantai (see [37]) defined the new mappings

$$
\begin{aligned}
& U_{n, 0}=I, \\
& U_{n, 1}=\lambda_{n, 1} T_{1} U_{n, 0}+\left(1-\lambda_{n, 1}\right) I, \\
& U_{n, 2}=\lambda_{n, 2} T_{2} U_{n, 1}+\left(1-\lambda_{n, 2}\right) U_{n, 1}, \\
& \vdots \\
& U_{n, N-1}=\lambda_{n, N-1} T_{N-1} U_{n, N-2}+\left(1-\lambda_{n, N-1}\right) U_{n, N-2}, \\
& K_{n}=U_{n, N}=\lambda_{n, N} T_{N} U_{n, N-1}+\left(1-\lambda_{n, N}\right) U_{n, N-1},
\end{aligned}
$$

where $\left\{\lambda_{n, i}\right\}_{i}^{N} \subset(0,1]$. Such a mapping $K_{n}$ is called the $K$-mapping generated by $T_{1}, T_{2}, \cdots, T_{N}$ and $\left\{\lambda_{n, 1}\right\},\left\{\lambda_{n, 2}\right\}, \cdots,\left\{\lambda_{n, N}\right\}$. Nonexpansivity of each $T_{i}$ ensures the nonexpansivity of $K_{n}$ Also following they defined the new mappings

$$
\begin{aligned}
& U_{0}=I, \\
& U_{1}=\lambda_{1} T_{1} U_{0}+\left(1-\lambda_{1}\right) I, \\
& U_{2}=\lambda_{2} T_{2} U_{1}+\left(1-\lambda_{2}\right) U_{1}, \\
& \vdots \\
& U_{N-1}=\lambda_{N-1} T_{N-1} U_{N-2}+\left(1-\lambda_{N-1}\right) U_{N-2}, \\
& K=U_{N}=\lambda_{N} T_{N} U_{N-1}+\left(1-\lambda_{N}\right) U_{N-1},
\end{aligned}
$$

where $\lambda_{1}, \lambda_{2}, \cdots, \lambda_{N} \in(0,1]$ such that $0<\lambda_{i}<1$ for all $i=1,2, \cdots, N-1$ and $0<\lambda_{N} \leq 1$. Such a mapping $K$ is called the $K$-mapping generated by $T_{1}, T_{2}, \cdots, T_{N}$ and $\lambda_{1}, \lambda_{2}, \cdots, \lambda_{N}$. In [37], Lemma 2.9 and Lemma 2.10, its shown that

$$
\operatorname{Fix}(K)=\cap_{i=1}^{N} \operatorname{Fix}\left(T_{i}\right)
$$

and $\lim _{n \rightarrow \infty}\left\|K_{n} x-K x\right\|=0$ for all $x \in C$, where $K_{n}$ and $K$ are the $K$-mappings defined by (1.16) and (1.17), respectively. Its important tool for the proof of the main results in this paper. Moreover, Kangtunyakarn and Suantai (see [37]) introduced a new iterative scheme: $x_{1} \in H$ and $n \geq 1$,

$$
\left\{\begin{array}{l}
F\left(y_{n}, \eta\right)+\frac{1}{r_{n}}\left\langle\eta-y_{n}, y_{n}-x_{n}\right\rangle \geq 0, \forall \eta \in C, \\
x_{n+1}=\alpha_{n} \gamma f\left(x_{n}\right)+\beta x_{n}+\left(\left(1-\beta_{n}\right) I-\alpha_{n} A\right) K_{n} y_{n},
\end{array}\right.
$$

where $\gamma>0, \beta \in(0,1),\left\{\alpha_{n}\right\} \subset(0,1),\left\{r_{n}\right\} \subset(0, \infty)$ and
$K_{n}$ is the $K$-mapping defined by (1.16). They proved that under certain appropriate conditions imposed on $\left\{\alpha_{n}\right\}$, $\left\{r_{n}\right\}$ and $\left\{\lambda_{n, i}\right\} \quad(\forall i=1,2, \cdots, N)$, the sequences $\left\{x_{n}\right\}$ and $\left\{y_{n}\right\}$ generated by (1.18) converge strongly to

$$
x^{*} \in \cap_{i=1}^{N} \operatorname{Fix}\left(T_{i}\right) \cap E P(F),
$$

where

$$
x^{*}=P_{\cap_{i=1}^{N} F i x\left(T_{i}\right) \cap E P(F)}(\gamma f+(I-A)) x^{*} .
$$

Motivated by the recent works, we introduce a more general iterative algorithm for finding a common element of the set of common fixed points of a finite family of nonexpansive mappings, the set of solutions of a mixed equilibrium problem, and the set of solutions of the variational inequality problem for a relaxed cocoercive mapping in a real Hilbert space. The scheme is defined as follows: $x_{1} \in H$ and $\forall n \geq 1$,

$$
\left\{\begin{aligned}
F\left(y_{n}, \eta\right)+\varphi(\eta)-\varphi\left(y_{n}\right)+\frac{1}{r_{n}}\left\langle\eta-y_{n}, y_{n}-x_{n}\right\rangle \geq 0, \\
\forall \eta \in C, \\
x_{n+1}=\alpha_{n} \gamma f\left(K_{n} x_{n}\right)+\beta_{n} x_{n} \\
+\left(\left(1-\beta_{n}\right) I-\alpha_{n} A\right) K_{n} P_{C}\left(I-s_{n} B\right) y_{n},
\end{aligned}\right.
$$

where $\gamma>0,\left\{\alpha_{n}\right\},\left\{\beta_{n}\right\} \subset(0,1),\left\{r_{n}\right\} \subset(0, \infty)$, $\left\{s_{n}\right\} \subset[0, \infty), B: C \rightarrow H$ is a $\mu$-Lipschitzian, relaxed $(u, v)$-cocoercive mapping, $f$ is a contraction of $H$ into itself with a coefficient $\alpha(0<\alpha<1), \quad P_{C}$ is a projection of $H$ onto $C, A$ is a strongly positive linear bounded operator on $H, F$ is a mixed equilibrium bifunction, $\varphi: C \rightarrow \mathbb{R} \cup\{+\infty\}$ is a proper lower semicontinuous and convex function and $K_{n}$ is the $K$-mapping generated by $T_{1}, T_{2}, \cdots, T_{N}$ and $\left\{\lambda_{n, 1}\right\},\left\{\lambda_{n, 2}\right\}, \cdots,\left\{\lambda_{n, N}\right\}$. We prove that the sequences $\left\{x_{n}\right\}$ and $\left\{y_{n}\right\}$ generated by the iterative scheme (1.19) converge strongly to

$$
q \in \cap_{i=1}^{N} \operatorname{Fix}\left(T_{i}\right) \cap \operatorname{MEP}(F, \varphi) \cap V I(C, B),
$$

where

$$
q=P_{\wedge_{i=1}^{N} \operatorname{Fix}\left(T_{i}\right) \cap M E P(F, \varphi) \cap V I(C, B)}(\gamma f+(I-A)) q,
$$

which is the unique solution of the variational inequality for all $\langle(\gamma f-A) q, p-q\rangle \leq 0$

$$
p \in \cap_{i=1}^{N} \operatorname{Fix}\left(T_{i}\right) \cap \operatorname{MEP}(F, \varphi) \cap V I(C, B),
$$

and is also the optimality condition for the minimization problem

$$
\min _{x \in \cap_{i=1}^{N} \operatorname{Fix}\left(T_{i}\right) \cap M E P(F, \varphi) \cap V(C, B)} \frac{1}{2}\langle A x, x\rangle-h(x),
$$

where $h$ is a potential function for $\gamma f$ (i.e., $h^{\prime}(x)=\gamma f(x)$ for $\left.x \in H\right)$. 


\section{Preliminaries and Lemmas}

In this section, we collect and give some useful lemmas that will be used for our main result in the next section.

A mapping $B$ is called $v$-strongly monotone, if each $x, y \in C$, we have

$$
\langle B x-B y, x-y\rangle \geq v\|x-y\|^{2},
$$

for a constant $v>0$, which implies that

$\|B x-B y\| \geq v\|x-y\|$, so that $B$ is $v$-expansive and when $v=1$, it is expansive. $B$ is said to be $v$-cocoercive (see [8] and [9]), if for each $x, y \in C$, we have

$$
\langle B x-B y, x-y\rangle \geq v\|B x-B y\|^{2},
$$

for a constant $v>0$. Clearly, every $v$-cocoercive mapping $B$ is $\frac{1}{v}$-Lipschitz continuous. $B$ is called relaxed $u$-cocoercive, if there exists a constant $u>0$ such that

$$
\langle B x-B y, x-y\rangle \geq(-\mu)\|B x-B y\|^{2},
$$

for all $x, y \in C . B$ is said to be relaxed $(u, v)$-cocoercive, if there exist two constants $u, v>0$ such that

$$
\langle B x-B y, x-y\rangle \geq(-u)\|B x-B y\|^{2}+v\|x-y\|^{2}
$$

for all $x, y \in C$, for $u=0, B$ is $v$-strongly monotone.

It is worth mentioning that the class of mappings which are relaxed $(u, v)$-cocoercive more general than the class of strongly monotone mappings. It is easy to see that if $B$ is a $v$-strongly monotone mapping, then it is a relaxed $(u, v)$-cocoercive mapping (see [10]).

It is well known that for all $x, y \in H$ and $\lambda \in[0,1]$ there holds

$$
\begin{aligned}
& \|\lambda x+(1-\lambda) y\|^{2} \\
& =\lambda\|x\|^{2}+(1-\lambda)\|y\|^{2}-\lambda(1-\lambda)\|x-y\|^{2} .
\end{aligned}
$$

Recall that a space $X$ is said to satisfy Opial's condition (see [38]) if $x_{n} \rightarrow x$ weakly as $n \rightarrow \infty$ and $x \neq y$ for all $y \in X$, then

$$
\limsup _{n \rightarrow \infty}\left\|x_{n}-x\right\|<\limsup _{n \rightarrow \infty}\left\|x_{n}-y\right\| .
$$

A set-valued mapping $T: H \rightarrow 2^{H}$ is called monotone if for all $x, y \in H, u \in T x$ and $v \in T y$ imply $\langle x-y, u-v\rangle \geq 0$.

A monotone mapping $T: H \rightarrow 2^{H}$ is maximal if graph $G(T)$ of $T$ is not properly contained in the graph of any other monotone mapping. It is known that a monotone mapping $T$ is maximal if and only if for $(x, u) \in H \times H,\langle x-y, u-v\rangle \geq 0$ for every $(y, v) \in G(T)$ implies $u \in T x$. Let $B$ be a monotone mapping of $C$ into $H$ and let $N_{C} v$ be normal cone to $C$ at $v \in C$, i.e.,

$$
N_{C} v=\{w \in H:\langle v-u, w\rangle \geq 0, \forall u \in C\}
$$

and define

$$
T v= \begin{cases}B v+N_{C} v, & v \in C, \\ \varnothing, & v \notin C\end{cases}
$$

Then $T$ is a maximal monotone and $0 \in T V$ if and only if $v \in V I(C, B)$; see [39].

In the sequel, the following lemmas are needed to prove our main results.

Lemma 2.1. (see $[4,5])$. Assume that $\left\{a_{n}\right\}$ is a sequence of nonnegative real numbers such that

$$
a_{n+1} \leq\left(1-\gamma_{n}\right) a_{n}+\delta_{n},
$$

where $\gamma_{n}$ is a sequence in $(0,1)$ and $\left\{\delta_{n}\right\}$ is a sequence such that

1) $\sum_{n=1}^{\infty} \gamma_{n}=\infty$;

2) $\limsup _{n \rightarrow \infty} \frac{\delta_{n}}{\gamma_{n}} \leq 0$ or $\sum_{n=1}^{\infty}\left|\delta_{n}\right|<\infty$. Then $\lim _{n \rightarrow \infty} a_{n}=0$.

Lemma 2.2. (see [3]). Assume $A$ is a strong positive linear bounded operator on a Hilbert space $H$ with coefficient $\bar{\gamma}>0$ and $0<\rho \leq\|A\|^{-1}$. Then $\|I-\rho A\| \leq 1-\rho \bar{\gamma}$.

Lemma 2.3. (see [40]). Let $\left\{x_{n}\right\}$ and $\left\{y_{n}\right\}$, be bounded sequences in a Banach space $X$ and let $\left\{\beta_{n}\right\}$ be a sequence in $[0,1]$ with

$$
0<\liminf _{n \rightarrow \infty} \beta_{n} \leq \limsup _{n \rightarrow \infty} \beta_{n}<1 .
$$

Suppose $x_{n+1}=\left(1-\beta_{n}\right) y_{n}+\beta_{n} x_{n}$ for all integers $n \geq 0$ and $\limsup _{n \rightarrow \infty}\left(\left\|y_{n+1}-y_{n}\right\|-\left\|x_{n+1}-x_{n}\right\|\right) \leq 0$.

Then

$$
\lim _{n \rightarrow \infty}\left\|y_{n}-x_{n}\right\|=0 .
$$

Lemma 2.4. (see [37]). Let $C$ be a nonempty closed convex set of a strictly convex Banach space. Let $\left\{T_{i}\right\}_{i=1}^{N}$ be a finite family of nonexpansive mappings of $C$ into itself with $\cap_{i=1}^{N} \operatorname{Fix}\left(T_{i}\right) \neq \varnothing$. and let $\lambda_{1}, \lambda_{2}, \cdots, \lambda_{N}$ be real numbers such that $0<\lambda_{i}<1$ for every

$i=1,2, \cdots, N-1$ and $0<\lambda_{N} \leq 1$. Let $K$ be the $K$-mapping generated by $T_{1}, T_{2}, \cdots, T_{N}$ and $\lambda_{1}, \lambda_{2}, \cdots, \lambda_{N}$. Then $\operatorname{Fix}(K)=\cap_{i=1}^{N} \operatorname{Fix}\left(T_{i}\right)$.

Lemma 2.5. (see [37]). Let $C$ be a nonempty convex subset of a Banach space. Let $\left\{T_{i}\right\}_{i=1}^{N}$ be a finite family of nonexpansive mappings of $C$ into itself and $\left\{\lambda_{n, i}\right\}_{i=1}^{N}$ be sequences in $[0,1]$ such that $\lambda_{n, i} \rightarrow \lambda_{i}(i=1, \cdots, N)$. Moreover for every $n \in \mathbb{N}$, let $K$ and $K_{n}$ be the $K$ mappings generated by $T_{1}, T_{2}, \cdots, T_{N}$ and $\lambda_{1}, \lambda_{2}, \cdots, \lambda_{N}$ and $T_{1}, T_{2}, \cdots, T_{N}$ and $\left\{\lambda_{n, 1}\right\},\left\{\lambda_{n, 2}\right\}, \cdots,\left\{\lambda_{n, N}\right\}$, respectively. Then for every $x \in C$, it follows that

$$
\lim _{n \rightarrow \infty}\left\|K_{n} x-K x\right\|=0 .
$$


For solving the mixed equilibrium problem, let us give the following assumptions for a bifunction $F, \varphi$ and the set $C$ :

(A1) $F(x, x)=0$ for all $x \in C$;

(A2) $F$ is monotone, i.e., $F(x, y)+F(y, x) \leq 0$ for all $x, y \in C$;

(A3) For each $x, y, z \in C$,

$$
\lim _{t \rightarrow 0} F(t z+(1-t) x, y) \leq F(x, y)
$$

(A4) For each $x \in C, \quad y \mapsto F(x, y)$ is convex and lower semicontinuous;

(B1) For each $x \in H$ and $r>0$, there exists a bounded subset $D_{x} \subset C$ and $y_{x} \in C$ such that for any $z \in C D_{x}$,

$$
F(z, y)+\varphi\left(y_{x}\right)+\frac{1}{r}\left\langle y_{x}-z, z-x\right\rangle<\varphi(z) ;
$$

(B2) $C$ is a bounded set.

By a similar argument as in the proof of Lemma 2.3 in [18], we have the following result.

Lemma 2.6. Let $C$ be a nonempty closed convex subset of a Hilbert space $H$ and let $F$ be a mixed equilibrium bifunction of $C \times C$ into $\mathbb{R}$ satisfying conditions (A1)(A4) and let $\varphi: C \rightarrow \mathbb{R} \cup\{+\infty\}$ be a proper lower semicontinuous and convex function. Assume that either (B1) or (B2) holds. For $r>0$ and $x \in H$, define a mapping $T_{r}: H \rightarrow C$ as follows:

$$
\begin{aligned}
T_{r}(x)= & \{z \in C: F(z, y)+\varphi(y) \\
& \left.+\frac{1}{r}\langle y-z, z-x\rangle \geq \varphi(z), \forall y \in C\right\}
\end{aligned}
$$

for all $x \in H$. Then $T_{r}$ is well defined and the following hold:

1) $T_{r}$ is single-valued;

2) $T_{r}$ is firmly nonexpansive, i.e., for any $x, y \in H$,

$$
\left\|T_{r} x-T_{r} y\right\|^{2} \leq\left\langle T_{r} x-T_{r} y, x-y\right\rangle ;
$$

3) $\operatorname{Fix}\left(T_{r}\right)=\operatorname{MEP}(F, \varphi)$;

4) $\operatorname{MEP}(F, \varphi)$ is closed and convex.

Remark 2.7. We remark that Lemma 1.6 is not a consequence of Lemma 3.1 in [14], because the condition of the sequential continuity from the weak topology to the strong topology for the derivative $K^{\prime}$ of the function $K: C \rightarrow \mathbb{R}$ does not cover the case

$$
K(x)=\frac{\|x\|^{2}}{2} .
$$

The following lemma is well known.

Lemma 2.8. In a real Hilbert space $H$, there holds the following inequality

$$
\|x+y\|^{2} \leq\|x\|^{2}+2\langle y, x+y\rangle
$$

for all $x, y \in H$.

\section{Main Results}

Theorem 3.1. Let $H$ be a real Hilbert space, $C$ a nonempty closed convex subset of $H, B$ a $\mu$-Lipschitzian, relaxed $(u, v)$-cocoercive mapping of $C$ into $H, F$ a bifunction from $C \times C$ to $\mathbb{R}$ which satisfies (A1)-(A4), $\varphi: C \rightarrow \mathbb{R} \cup\{+\infty\}$ a proper lower semicontinuous and convex function and $T_{1}, T_{2}, \cdots, T_{N}$ a finite family of nonexpansive mappings of $C$ into $H$ such that the common fixed points set

$$
\cap_{i=1}^{N} \operatorname{Fix}\left(T_{i}\right) \cap \operatorname{MEP}(F, \varphi) \cap V I(C, B) \neq \varnothing .
$$

Let $f$ be a contraction of $H$ into itself with a coefficient $\alpha(0<\alpha<1)$ and $A$ a strongly positive linear bounded operator on $H$ with coefficient $\bar{\gamma}>0$ such that $\|A\| \leq 1$. Assume that $0<\gamma<\frac{\bar{\gamma}}{\alpha}$ and either (B1) or (B2) holds. Let $\lambda_{1}, \lambda_{2}, \cdots, \lambda_{N}$ be real numbers such that $0<\lambda_{i}<1$ for every $i=1,2, \cdots, N-1$ and $0<\lambda_{N} \leq 1$, $\lambda_{n, i} \rightarrow \lambda_{i}(i=1, \cdots, N),\left\{r_{n}\right\} \subset(0, \infty),\left\{s_{n}\right\} \subset[0, \infty)$ and $\left\{\alpha_{n}\right\},\left\{\beta_{n}\right\}$ two real sequences in $(0,1)$ satisfying the following conditions:

$$
\begin{aligned}
& \text { (C1) } \lim _{n \rightarrow \infty} \alpha_{n}=0 \text { and } \sum_{n=1}^{\infty} \alpha_{n}=\infty ; \\
& \text { (C2) } \sum_{n=1}^{\infty}\left|s_{n+1}-s_{n}\right|<\infty \text {; } \\
& \text { (C3) } \liminf _{n \rightarrow \infty} r_{n}>0 \text { and } \lim _{n \rightarrow \infty} \frac{r_{n}}{r_{n+1}}=1 \text { (this is weaker }
\end{aligned}
$$
than the condition ); $\lim _{n \rightarrow \infty}\left|r_{n+1}-r_{n}\right|=0$;

(C4) $0<\liminf _{n \rightarrow \infty} \beta_{n} \leq \limsup _{n \rightarrow \infty} \beta_{n}<1$;

(C5) $\left\{s_{n}\right\} \subset[a, b]$ for some $a, b$ with $0 \leq a \leq b \leq \frac{2\left(v-u \mu^{2}\right)}{\mu^{2}}, v \geq u \mu^{2}$;

(C6) $\sum_{n=0}^{\infty}\left|\lambda_{n, i}-\lambda_{n-1, i}\right|<\infty$ for all $i=1,2, \cdots, N$.

Then, the sequences $\left\{x_{n}\right\}$ and $\left\{y_{n}\right\}$ generated iteratively by (1.19) converge strongly to

$$
q \in \cap_{i=1}^{N} \operatorname{Fix}\left(T_{i}\right) \cap \operatorname{MEP}(F, \varphi) \cap V I(C, B),
$$

where

$$
q=P_{\cap_{i=1}^{N} \operatorname{Fix}\left(T_{i}\right) \cap M E P(F, \varphi) \cap V I(C, B)}(\gamma f+(I-A)) q,
$$

which solves the following variational inequality:

$$
\langle(\gamma f-A) q, p-q\rangle \leq 0
$$

for all 


$$
p \in \cap_{i=1}^{N} \operatorname{Fix}\left(T_{i}\right) \cap \operatorname{MEP}(F, \varphi) \cap V I(C, B) .
$$

Proof Since $\alpha_{n} \rightarrow 0$ as $n \rightarrow \infty$ by the condition (C1), we may assume, without loss of generality, that

$$
0<\alpha_{n} \leq\left(1-\beta_{n}\right)\|A\|^{-1}
$$

for all $n$. We also have $0<\alpha_{n} \leq\|A\|^{-1}$ for all $n$. By using Lemma 2.2, we have

$$
\left\|I-\alpha_{n} A\right\| \leq 1-\alpha_{n} \bar{\gamma} .
$$

Since $A$ is a strongly positive linear bounded operator on a Hilbert space $H$, we have

and

$$
\langle A x, x\rangle \geq \bar{\gamma}\|x\|^{2}
$$

$$
\begin{aligned}
& \|A\|=\sup \{|\langle A x, x\rangle|: x \in H,\|x\|=1\} . \\
& \begin{aligned}
\left\|\left(I-s_{n} B\right) x-\left(I-s_{n} B\right) y\right\|^{2} & =\left\|(x-y)-s_{n}(B x-B y)\right\|^{2}=\|x-y\|^{2}-2 s_{n}\langle x-y, B x-B y\rangle+s_{n}^{2}\|B x-B y\|^{2} \\
& \leq\|x-y\|^{2}-2 s_{n}\left(-u\|B x-B y\|^{2}+v\|x-y\|^{2}\right)+s_{n}^{2}\|B x-B y\|^{2} \\
& \leq\|x-y\|^{2}+2 s_{n} \mu^{2} u\|x-y\|^{2}-2 s_{n} v\|x-y\|^{2}+\mu^{2} s_{n}^{2}\|x-y\|^{2} \\
& =\left(1+2 s_{n} \mu^{2} u-2 s_{n} v+\mu^{2} s_{n}^{2}\right)\|x-y\|^{2} \leq\|x-y\|^{2}
\end{aligned}
\end{aligned}
$$

This shows that $\left(1-\beta_{n}\right) I-\alpha_{n} A$ is positive. It follows that

$$
\begin{aligned}
& \left\|\left(1-\beta_{n}\right) I-\alpha_{n} A\right\| \\
& =\sup \left\{\mid\left\langle\left(\left(1-\beta_{n}\right) I-\alpha_{n} A\right) x, x\right\rangle: x \in H,\|x\|=1\right\} \\
& =\sup \left\{1-\beta_{n}-\alpha_{n}\langle A x, x\rangle: x \in H,\|x\|=1\right\} \leq 1-\beta_{n}-\alpha_{n} \bar{\gamma} .
\end{aligned}
$$

Next, we will assume that $\|I-A\| \leq 1-\bar{\gamma}$. First, we show $I-s_{n} B$ is nonexpansive. Indeed, from the relaxed $(u, v)$-cocoercive and $\mu$-Lipschitzian definition on $B$
We shall divide our proof into 5 steps.

Step 1. We shall show that the sequence $\left\{x_{n}\right\}$ is bounded. Let

$$
x^{*} \in \cap_{i=1}^{N} \operatorname{Fix}\left(T_{i}\right) \cap \operatorname{MEP}(F, \varphi) \cap V I(C, B) .
$$

Since $y_{n}=T_{r_{n}} x_{n} \in \operatorname{dom} \varphi$, we have

$$
\begin{aligned}
\left\|y_{n}-x^{*}\right\|= & \left\|T_{r_{n}} x_{n}-T_{r_{n}} x^{*}\right\| \leq\left\|x_{n}-x^{*}\right\| . \quad \text { (3.1) Using (1.19), (3.1) and (3.2), we have } \\
\left\|x_{n+1}-x^{*}\right\| & =\left\|\alpha_{n} \gamma f\left(K_{n} x_{n}\right)+\beta_{n} x_{n}+\left(\left(1-\beta_{n}\right) I-\alpha_{n} A\right) K_{n} z_{n}-x^{*}\right\| \\
& =\left\|\alpha_{n}\left(\gamma f\left(K_{n} x_{n}\right)-A x^{*}\right)+\beta_{n}\left(x_{n}-x^{*}\right)+\left(\left(1-\beta_{n}\right) I-\alpha_{n} A\right)\left(K_{n} z_{n}-x^{*}\right)\right\| \\
& \leq\left(1-\beta_{n}-\alpha_{n} \bar{\gamma}\right)\left\|K_{n} z_{n}-x^{*}\right\|+\beta_{n}\left\|x_{n}-x^{*}\right\|+\alpha_{n}\left\|\gamma f\left(K_{n} x_{n}\right)-A x^{*}\right\| \\
& \leq\left(1-\beta_{n}-\alpha_{n} \bar{\gamma}\right)\left\|z_{n}-x^{*}\right\|+\beta_{n}\left\|x_{n}-x^{*}\right\|+\alpha_{n}\left\|\gamma f\left(K_{n} x_{n}\right)-\gamma f\left(x^{*}\right)+\gamma f\left(x^{*}\right)-A x^{*}\right\| \\
& \leq\left(1-\beta_{n}-\alpha_{n} \bar{\gamma}\right)\left\|x_{n}-x^{*}\right\|+\beta_{n}\left\|x_{n}-x^{*}\right\|+\alpha_{n} \gamma\left\|f\left(K_{n} x_{n}\right)-f\left(x^{*}\right)\right\|+\alpha_{n}\left\|\gamma f\left(x^{*}\right)-A x^{*}\right\| \\
& \leq\left(1-\alpha_{n} \bar{\gamma}\right)\left\|x_{n}-x^{*}\right\|+\alpha_{n} \gamma \alpha\left\|x_{n}-x^{*}\right\|+\alpha_{n}\left\|\gamma f\left(x^{*}\right)-A x^{*}\right\| \\
& =\left(1-(\bar{\gamma}-\gamma \alpha) \alpha_{n}\right)\left\|x_{n}-x^{*}\right\|+\alpha_{n}\left\|\gamma f\left(x^{*}\right)-A x^{*}\right\|,
\end{aligned}
$$

which gives that

$$
\left\|x_{n}-x^{*}\right\| \leq \max \left\{\left\|x_{0}-x^{*}\right\|, \frac{\left\|\gamma f\left(x^{*}\right)-A x^{*}\right\|}{\bar{\gamma}-\gamma \alpha}\right\}, n \geq 0 .
$$

Hence $\left\{x_{n}\right\}$ is bounded, so are $\left\{y_{n}\right\},\left\{z_{n}\right\},\left\{K_{n} z_{n}\right\}$,
$\left\{B y_{n}\right\}$ and $\left\{f\left(K_{n} x_{n}\right)\right\}$.

Step 2. We will show that

$$
\lim _{n \rightarrow \infty}\left\|x_{n+1}-x_{n}\right\|=0 \text {. }
$$

Observing that $y_{n}=T_{r_{n}} x_{n} \in \operatorname{dom} \varphi$ and $y_{n+1}=T_{r_{n+1}} x_{n+1} \in \operatorname{dom} \varphi$, we have 


$$
F\left(y_{n}, \eta\right)+\varphi(\eta)-\varphi\left(y_{n}\right)+\frac{1}{r_{n}}\left\langle\eta-y_{n}, y_{n}-x_{n}\right\rangle \geq 0, \forall \eta \in C
$$

and

$$
F\left(y_{n+1}, \eta\right)+\varphi(\eta)-\varphi\left(y_{n+1}\right)+\frac{1}{r_{n+1}}\left\langle\eta-y_{n+1}, y_{n+1}-x_{n+1}\right\rangle \geq 0, \forall \eta \in C .
$$

Putting $\eta=y_{n+1}$ in (3.3) and $\eta=y_{n}$ in (3.4), we have

$$
\begin{aligned}
& F\left(y_{n}, y_{n+1}\right)+\varphi\left(y_{n+1}\right)-\varphi\left(y_{n}\right) \\
& +\frac{1}{r_{n}}\left\langle y_{n+1}-y_{n}, y_{n}-x_{n}\right\rangle \geq 0
\end{aligned}
$$

and

$$
\begin{aligned}
& F\left(y_{n+1}, y_{n}\right)+\varphi\left(y_{n}\right)-\varphi\left(y_{n+1}\right) \\
& +\frac{1}{r_{n+1}}\left\langle y_{n}-y_{n+1}, y_{n+1}-x_{n+1}\right\rangle \geq 0 .
\end{aligned}
$$

Summing up the last two inequalities and using Lemma 2.6 (A2), we obtain

$$
\left\langle y_{n+1}-y_{n}, \frac{y_{n}-x_{n}}{r_{n}}-\frac{y_{n+1}-x_{n+1}}{r_{n+1}}\right\rangle \geq 0 \text {. }
$$

That is,

$$
\left\langle y_{n+1}-y_{n}, y_{n}-y_{n+1}+y_{n+1}-x_{n}-\frac{r_{n}}{r_{n+1}}\left(y_{n+1}-x_{n+1}\right)\right\rangle \geq 0 \text {. }
$$

$$
\begin{aligned}
\left\|z_{n+1}-z_{n}\right\| & =\left\|P_{C}\left(I-S_{n+1} B\right) y_{n+1}-P_{C}\left(I-S_{n} B\right) y_{n}\right\| \leq\left\|\left(I-s_{n+1} B\right) y_{n+1}-\left(I-s_{n} B\right) y_{n}\right\| \\
& =\left\|\left(I-s_{n+1} B\right) y_{n+1}-\left(I-s_{n+1} B\right) y_{n}+\left(s_{n}-s_{n+1}\right) B y_{n}\right\| \leq\left\|y_{n+1}-y_{n}\right\|+\left|s_{n}-s_{n+1}\right|\left\|B y_{n}\right\| \\
& \leq\left\|x_{n+1}-x_{n}\right\|+M_{1}\left|1-\frac{r_{n}}{r_{n+1}}\right|+\left|s_{n}-s_{n+1}\right|\left\|B y_{n}\right\| \leq\left\|x_{n+1}-x_{n}\right\|+M_{1}\left|1-\frac{r_{n}}{r_{n+1}}\right|+M_{2}\left|s_{n}-s_{n+1}\right|,
\end{aligned}
$$

Since $I-S_{n} B$ is nonexpansive and $z_{n}=P_{C}\left(I-s_{n} B\right) y_{n}$, using (3.5), we also have

where $M_{2}$ is an appropriate constant such that

$$
M_{2}=\sup _{n \geq 1}\left\|B y_{n}\right\| .
$$

Define

$$
u_{n}=\frac{x_{n+1}-\beta_{n} x_{n}}{1-\beta_{n}}
$$

for all $n \geq 0$ so that

$$
x_{n+1}=\left(1-\beta_{n}\right) u_{n}+\beta_{n} x_{n} .
$$

It follows that

$$
\begin{aligned}
u_{n+1}-u_{n}= & \frac{x_{n+2}-\beta_{n+1} x_{n+1}}{1-\beta_{n+1}}-\frac{x_{n+1}-\beta_{n} x_{n}}{1-\beta_{n}} \\
& =\frac{\alpha_{n+1} \gamma f\left(K_{n+1} x_{n+1}\right)+\left(\left(1-\beta_{n+1}\right) I-\alpha_{n+1} A\right) K_{n+1} z_{n+1}}{1-\beta_{n+1}}-\frac{\alpha_{n} \gamma f\left(K_{n} x_{n}\right)+\left(\left(1-\beta_{n}\right) I-\alpha_{n} A\right) K_{n} z_{n}}{1-\beta_{n}} \\
& =\left(\frac{\alpha_{n+1}}{1-\beta_{n+1}}\right) \gamma f\left(K_{n+1} x_{n+1}\right)-\left(\frac{\alpha_{n}}{1-\beta_{n}}\right) \gamma f\left(K_{n} x_{n}\right)+K_{n+1} z_{n+1}-K_{n} z_{n}+\left(\frac{\alpha_{n}}{1-\beta_{n}}\right) A K_{n} z_{n}-\left(\frac{\alpha_{n+1}}{1-\beta_{n+1}}\right) A K_{n+1} z_{n+1} \\
& =\frac{\alpha_{n+1}}{1-\beta_{n+1}}\left(\gamma f\left(K_{n+1} x_{n+1}\right)-A K_{n+1} z_{n+1}\right)+\frac{\alpha_{n}}{1-\beta_{n}}\left(A K_{n} z_{n}-\gamma f\left(K_{n} x_{n}\right)\right)+K_{n+1} z_{n+1}-K_{n+1} z_{n}+K_{n+1} z_{n}-K_{n} z_{n} .
\end{aligned}
$$


Observe that $u_{n}=\frac{x_{n+1}-\beta_{n} x_{n}}{1-\beta_{n}}$ from (3.6), we obtain

$$
\begin{aligned}
\left\|u_{n+1}-u_{n}\right\|= & \left\|\frac{\alpha_{n+1}}{1-\beta_{n+1}}\left(\gamma f\left(K_{n+1} x_{n+1}\right)-A K_{n+1} z_{n+1}\right)+\frac{\alpha_{n}}{1-\beta_{n}}\left(A K_{n} z_{n}-\gamma f\left(K_{n} x_{n}\right)\right)+K_{n+1} z_{n+1}-K_{n+1} z_{n}+K_{n+1} z_{n}-K_{n} z_{n}\right\| \\
\leq & \frac{\alpha_{n+1}}{1-\beta_{n+1}}\left(\left\|\gamma f\left(K_{n+1} x_{n+1}\right)\right\|+\left\|A K_{n+1} z_{n+1}\right\|\right)+\frac{\alpha_{n}}{1-\beta_{n}}\left(\left\|A K_{n} z_{n}\right\|+\left\|\gamma f\left(K_{n} x_{n}\right)\right\|\right) \\
& +\left\|K_{n+1} z_{n+1}-K_{n+1} z_{n}\right\|+\left\|K_{n+1} z_{n}-K_{n} z_{n}\right\| \\
\leq & \frac{\alpha_{n+1}}{1-\beta_{n+1}}\left(\left\|\gamma f\left(K_{n+1} x_{n+1}\right)\right\|+\left\|A K_{n+1} z_{n+1}\right\|\right)+\frac{\alpha_{n}}{1-\beta_{n}}\left(\left\|A K_{n} z_{n}\right\|+\left\|\gamma f\left(K_{n} x_{n}\right)\right\|\right)+\left\|z_{n+1}-z_{n}\right\|+\left\|K_{n+1} z_{n}-K_{n} z_{n}\right\| \\
\leq & \frac{\alpha_{n+1}}{1-\beta_{n+1}}\left(\left\|\gamma f\left(K_{n+1} x_{n+1}\right)\right\|+\left\|A K_{n+1} z_{n+1}\right\|\right)+\frac{\alpha_{n}}{1-\beta_{n}}\left(\left\|A K_{n} z_{n}\right\|+\left\|\gamma f\left(K_{n} x_{n}\right)\right\|\right)+\left\|X_{n+1}-x_{n}\right\| \\
& +M_{1}\left|1-\frac{r_{n}}{r_{n+1}}\right|+M_{2}\left|s_{n}-s_{n+1}\right|+\left\|K_{n+1} z_{n}-K_{n} z_{n}\right\| .
\end{aligned}
$$

Next we estimate $\left\|K_{n+1} z_{n}-K_{n} z_{n}\right\|$.

For $i \in\{2, \cdots, N-2\}$, we have

$$
\begin{aligned}
& \left\|U_{n+1, N-i} z_{n}-U_{n, N-i} z_{n}\right\| \\
& =\left\|\lambda_{n+1, N-i} T_{N-i} U_{n+1, N-i-1} z_{n}+\left(1-\lambda_{n+1, N-i}\right) U_{n+1, N-i-1} z_{n}-\lambda_{n, N-i} T_{N-i} U_{n, N-i-1} z_{n}-\left(1-\lambda_{n, N-i}\right) U_{n, N-i-1} z_{n}\right\| \\
& =\| \lambda_{n+1, N-i} T_{N-i} U_{n+1, N-i-1} z_{n}-\lambda_{n+1, N-i} T_{N-i} U_{n, N-i-1} z_{n}+\lambda_{n+1, N-i} T_{N-i} U_{n, N-i-1} z_{n}-\lambda_{n+1, N-i} U_{n, N-i-1} z_{n} \\
& \quad+\lambda_{n+1, N-i} U_{n, N-i-1} z_{n}+\left(1-\lambda_{n+1, N-i}\right) U_{n+1, N-i-1} z_{n}-\lambda_{n, N-i} T_{N-i} U_{n, N-i-1} z_{n}-\left(1-\lambda_{n, N-i}\right) U_{n, N-i-1} z_{n} \| \\
& \leq \lambda_{n+1, N-i}\left\|T_{N-i} U_{n+1, N-i-1} z_{n}-T_{N-i} U_{n, N-i-1} z_{n}\right\|+\left(1-\lambda_{n+1, N-i}\right)\left\|U_{n+1, N-i-1} z_{n}-U_{n, N-i-1} z_{n}\right\| \\
& \quad+\left|\lambda_{n+1, N-i}-\lambda_{n, N-i}\left\|T_{N-i} U_{n, N-i-1} z_{n}\right\|+\right| \lambda_{n+1, N-i}-\lambda_{n, N-i}\left\|U_{n, N-i-1} z_{n}\right\| \\
& \leq\left\|U_{n+1, N-i-1} z_{n}-U_{n, N-i-1} z_{n}\right\|+M_{3}\left|\lambda_{n+1, N-i}-\lambda_{n, N-i}\right|
\end{aligned}
$$

and

$$
\begin{aligned}
\left\|U_{n+1,1} z_{n}-U_{n, 1} z_{n}\right\| & =\left\|\lambda_{n+1,1} T_{1} z_{n}+\left(1-\lambda_{n+1,1}\right) z_{n}-\lambda_{n, 1} T_{1} z_{n}-\left(1-\lambda_{n, 1}\right) z_{n}\right\| \\
& \leq\left|\lambda_{n+1,1}-\lambda_{n, 1}\right|\left|T_{1} z_{n}\left\|+\left|\lambda_{n+1,1}-\lambda_{n, 1}\right|\right\| z_{n} \| \leq\right| \lambda_{n+1,1}-\lambda_{n, 1} \mid M_{3},
\end{aligned}
$$

where

$$
M_{3}=\sup \left\{\sum_{i=2}^{N}\left(\left\|T_{i} U_{n, i-1} z_{n}\right\|+\left\|U_{n, i-1} z_{n}\right\|\right)+\left\|T_{1} z_{n}\right\|+\left\|z_{n}\right\|\right\}<\infty .
$$

Using (3.8) and (3.9), we have

$$
\begin{aligned}
\left\|K_{n+1} z_{n}-K_{n} z_{n}\right\| & =\mid U_{n+1, N} z_{n}-U_{n, N} z_{n} \| \\
& \leq\left|U_{n+1, N-1} z_{n}-U_{n, N-1} z_{n} \|+M_{3}\right| \lambda_{n+1, N}-\lambda_{n, N} \mid \\
& \leq\left|U_{n+1, N-2} z_{n}-U_{n, N-2} z_{n} \|+M_{3}\right| \lambda_{n+1, N-1}-\lambda_{n, N-1}\left|+M_{3}\right| \lambda_{n+1, N}-\lambda_{n, N} \mid \\
& \vdots \\
& \leq|| U_{n+1,1} z_{n}-U_{n, 1} z_{n} \|+M_{3} \sum_{i=2}^{N}\left|\lambda_{n+1, i}-\lambda_{n, i}\right| \\
& \leq M_{3} \sum_{i=1}^{N}\left|\lambda_{n+1, i}-\lambda_{n, i}\right| .
\end{aligned}
$$

Substitute (3.10) into (3.7) yields that 


$$
\begin{aligned}
\left\|u_{n+1}-u_{n}\right\|-\left\|x_{n+1}-x_{n}\right\| \leq & \frac{\alpha_{n+1}}{1-\beta_{n+1}}\left(\left\|\gamma f\left(K_{n+1} x_{n+1}\right)\right\|+\left\|A K_{n+1} z_{n+1}\right\|\right)+\frac{\alpha_{n}}{1-\beta_{n}}\left(\left\|A K_{n} z_{n}\right\|+\left\|\gamma f\left(K_{n} x_{n}\right)\right\|\right) \\
& +M_{1}\left|1-\frac{r_{n}}{r_{n+1}}\right|+M_{2}\left|s_{n}-s_{n+1}\right|+M_{3} \sum_{i=1}^{N}\left|\lambda_{n+1, i}-\lambda_{n, i}\right|
\end{aligned}
$$

which implies that (noting that $(\mathrm{C} 1),(\mathrm{C} 2),(\mathrm{C} 3),(\mathrm{C} 4)$ and (C6))

$$
\limsup _{n \rightarrow \infty}\left(\left\|u_{n+1}-u_{n}\right\|-\left\|x_{n+1}-x_{n}\right\|\right) \leq 0 .
$$

Hence by Lemma 2.3, we have

$$
\lim _{n \rightarrow \infty}\left\|u_{n}-x_{n}\right\|=0 .
$$

Using (3.11) and we have $x_{n+1}=\left(1-\beta_{n}\right) u_{n}+\beta_{n} x_{n}$,

$$
\lim _{n \rightarrow \infty}\left\|x_{n+1}-x_{n}\right\|=\lim _{n \rightarrow \infty}\left(1-\beta_{n}\right)\left\|u_{n}-x_{n}\right\|=0
$$

Step 3. We shall show that

$$
\begin{aligned}
\lim _{n \rightarrow \infty}\left\|x_{n}-K_{n} z_{n}\right\| & =\lim _{n \rightarrow \infty}\left\|x_{n}-y_{n}\right\|=\lim _{n \rightarrow \infty}\left\|y_{n}-K_{n} z_{n}\right\| \\
& =\lim _{n \rightarrow \infty}\left\|z_{n}-K_{n} z_{n}\right\|=0,
\end{aligned}
$$

where $y_{n}=T_{r_{n}} x_{n}$.

Note that

$$
\begin{aligned}
\left\|x_{n}-K_{n} z_{n}\right\| & =\left\|x_{n}-x_{n+1}+x_{n+1}-K_{n} z_{n}\right\| \leq\left\|x_{n+1}-x_{n}\right\|+\left\|x_{n+1}-K_{n} z_{n}\right\| \\
& \leq\left\|x_{n+1}-x_{n}\right\|+\left\|\alpha_{n} \gamma f\left(K_{n} x_{n}\right)+\beta_{n} x_{n}+\left(\left(1-\beta_{n}\right) I-\alpha_{n} A\right) K_{n} z_{n}-K_{n} z_{n}\right\| \\
& =\left\|x_{n+1}-x_{n}\right\|+\left\|\alpha_{n}\left(\gamma f\left(K_{n} x_{n}\right)-A K_{n} z_{n}\right)+\left(\left(1-\beta_{n}\right) I-\alpha_{n} A\right)\left(K_{n} z_{n}-K_{n} z_{n}\right)+\beta_{n}\left(x_{n}-K_{n} z_{n}\right)\right\| \\
& \leq\left\|x_{n+1}-x_{n}\right\|+\alpha_{n}\left\|\gamma f\left(K_{n} x_{n}\right)-A K_{n} z_{n}\right\|+\beta_{n}\left\|x_{n}-K_{n} z_{n}\right\| .
\end{aligned}
$$

This implies

$$
\begin{aligned}
& \left(1-\beta_{n}\right)\left\|x_{n}-K_{n} z_{n}\right\| \\
& \leq\left\|x_{n+1}-x_{n}\right\|+\alpha_{n}\left\|\gamma f\left(K_{n} x_{n}\right)-A K_{n} z_{n}\right\| .
\end{aligned}
$$

From condition (C1), (C4) and (3.12), we have

$$
\lim _{n \rightarrow \infty}\left\|x_{n}-K_{n} z_{n}\right\|=0 .
$$

Next we prove that

$$
\left\|x_{n}-y_{n}\right\| \rightarrow 0
$$

as $n \rightarrow \infty$.

Indeed, picking

$$
\begin{aligned}
x^{*} \in \cap_{i=1}^{N} \operatorname{Fix}\left(T_{i}\right) & \cap \operatorname{MEP}(F, \varphi) \cap V I(C, B) . \quad \text { (3.14) and Lemma } 2.8 \text { we have } \\
\left\|x_{n+1}-x^{*}\right\|^{2} & =\left\|\alpha_{n} \gamma f\left(K_{n} x_{n}\right)+\beta_{n} x_{n}+\left(\left(1-\beta_{n}\right) I-\alpha_{n} A\right) K_{n} z_{n}-x^{*}\right\|^{2} \\
& =\left\|\left(\left(1-\beta_{n}\right)\left(K_{n} z_{n}-x^{*}\right)+\beta_{n}\left(x_{n}-x^{*}\right)\right)+\alpha_{n}\left(\gamma f\left(K_{n} x_{n}\right)-A K_{n} z_{n}\right)\right\|^{2} \\
& \leq\left\|\left(1-\beta_{n}\right)\left(K_{n} z_{n}-x^{*}\right)+\beta_{n}\left(x_{n}-x^{*}\right)\right\|^{2}+2 \alpha_{n}\left\langle\rho_{n}, x_{n+1}-x^{*}\right\rangle \\
& \leq\left(1-\beta_{n}\right)\left\|K_{n} z_{n}-x^{*}\right\|^{2}+\beta_{n}\left\|x_{n}-x^{*}\right\|^{2}+2 \lambda^{2} \alpha_{n} \\
& \leq\left(1-\beta_{n}\right)\left\|z_{n}-x^{*}\right\|^{2}+\beta_{n}\left\|x_{n}-x^{*}\right\|^{2}+2 \lambda^{2} \alpha_{n} \leq\left(1-\beta_{n}\right)\left\|y_{n}-x^{*}\right\|^{2}+\beta_{n}\left\|x_{n}-x^{*}\right\|^{2}+2 \lambda^{2} \alpha_{n} \\
& \leq\left(1-\beta_{n}\right)\left(\left\|x_{n}-x^{*}\right\|^{2}-\left\|x_{n}-y_{n}\right\|^{2}\right)+\beta_{n}\left\|x_{n}-x^{*}\right\|^{2}+2 \lambda^{2} \alpha_{n} \\
& =\left.\left\|x_{n}-x^{*}\right\|\right|^{2}-\left(1-\beta_{n}\right)\left\|x_{n}-y_{n}\right\|^{2}+2 \lambda^{2} \alpha_{n} .
\end{aligned}
$$

Since $y_{n}=T_{r_{n}} x_{n} \in \operatorname{dom} \varphi$ and $T_{r}$ is firmly nonexpansive, we obtain and hence

$$
\begin{aligned}
\left\|x^{*}-y_{n}\right\|^{2} & =\left\|T_{r_{n}} x^{*}-T_{r_{n}} x_{n}\right\|^{2} \leq\left\langle T_{r_{n}} x_{n}-T_{r_{n}} x^{*}, x_{n}-x^{*}\right\rangle \\
& =\left\langle y_{n}-x^{*}, x_{n}-x^{*}\right\rangle \\
& =\frac{1}{2}\left(\left\|y_{n}-x^{*}\right\|^{2}+\left\|x_{n}-x^{*}\right\|^{2}-\left\|x_{n}-y_{n}\right\|^{2}\right)
\end{aligned}
$$

Set $\rho_{n}=\gamma f\left(K_{n} x_{n}\right)-A K_{n} z_{n}$ and let $\lambda>0$ be an appropriate constant such that

$$
\lambda \geq \sup _{n, k}\left\{\left\|\rho_{n}\right\|,\left\|x_{k}-x^{*}\right\|\right\} .
$$

Therefore, from the convexity of \|\|$^{2}$, using (3.2), 
It follows that

$$
\begin{aligned}
& \left(1-\beta_{n}\right)\left\|x_{n}-y_{n}\right\|^{2} \leq\left\|x_{n}-x^{*}\right\|^{2}-\left\|x_{n+1}-x^{*}\right\|^{2}+2 \lambda^{2} \alpha_{n} \\
& =\left\|x_{n}-x_{n+1}\right\|^{2}+2\left\langle x_{n}-x_{n+1}, x_{n+1}-x^{*}\right\rangle+2 \lambda^{2} \alpha_{n} \leq\left\|x_{n}-x_{n+1}\right\|^{2}+2 \lambda\left\|x_{n}-x_{n+1}\right\|+2 \lambda^{2} \alpha_{n} .
\end{aligned}
$$

By using condition (C1), (C4) and (3.12), we have

$$
\lim _{n \rightarrow \infty}\left\|x_{n}-y_{n}\right\|=0 \text {. }
$$

From (3.13) and (3.15), we obtain

$$
\begin{gathered}
\left\|y_{n}-K_{n} z_{n}\right\| \leq\left\|y_{n}-x_{n}\right\|+\left\|x_{n}-K_{n} z_{n}\right\| \rightarrow 0 \\
(\text { as } n \rightarrow \infty) .
\end{gathered}
$$

From (3.11) and (3.13), we also obtain

$$
\lim _{n \rightarrow \infty}\left\|z_{n}-K_{n} z_{n}\right\|=0
$$

Step 4. We shall show that

$$
\limsup _{n \rightarrow \infty}\left\langle(\gamma f-A) q, x_{n}-q\right\rangle \leq 0,
$$

where $q$ is the unique solution of the variational inequality $\langle(\gamma f-A) q, p-q\rangle \leq 0$,

$$
\forall p \in \cap_{i=1}^{N} \operatorname{Fix}\left(T_{i}\right) \cap \operatorname{MEP}(F, \varphi) \cap V I(C, B) .
$$

Let $Q=P_{\cap_{i=1}^{N} \operatorname{Fix}\left(T_{i}\right) \cap M E P(F, \varphi) \cap V I(C, B)}$. Observe that $Q(\gamma f+(I-A))$ is a contraction. Indeed, for all $x$, $y \in H$ and $0<\gamma<\frac{\bar{\gamma}}{\alpha}$, we have

$$
\begin{aligned}
& \|Q(\gamma f+(I-A)) x-Q(\gamma f+(I-A)) y\| \\
& \leq\|(\gamma f+(I-A)) x-(\gamma f+(I-A)) y\| \\
& \leq \gamma\|f(x)-f(y)\|+\|I-A\|\|x-y\| \\
& \leq \gamma \alpha\|x-y\|+(1-\bar{\gamma})\|x-y\| \\
& =(\gamma \alpha+1-\bar{\gamma})\|x-y\| \leq\|x-y\| .
\end{aligned}
$$

Banach's Contraction Mapping Principle guarantees that $Q(\gamma f+(I-A))$ has a unique fixed point, say $q \in H$. That is,

$$
\begin{aligned}
q & =Q(\gamma f+(I-A)) q \\
& =P_{\cap_{i=1}^{N} \operatorname{Fix}\left(T_{i}\right) \cap M E P(F, \varphi) \cap V I(C, B)}(\gamma f+(I-A)) q,
\end{aligned}
$$

by (1.1) we obtain that $\langle(\gamma f-A) q, p-q\rangle \leq 0$ for all

$$
p \in \cap_{i=1}^{N} \operatorname{Fix}\left(T_{i}\right) \cap \operatorname{MEP}(F, \varphi) \cap V I(C, B) .
$$

Next, we show that

$$
\limsup _{n \rightarrow \infty}\left\langle(\gamma f-A) q, y_{n}-q\right\rangle \leq 0 .
$$

To see this, we choose a subsequence $\left\{y_{n_{i}}\right\}$ of $\left\{y_{n}\right\}$ such that

$$
\begin{aligned}
& \limsup _{n \rightarrow \infty}\left\langle(\gamma f-A q), y_{n}-q\right\rangle \\
& =\lim _{i \rightarrow \infty}\left\langle(\gamma f-A) q, y_{n_{i}}-q\right\rangle .
\end{aligned}
$$

Since $\left\{y_{n_{i}}\right\}$ is bounded, there exists $\left\{y_{n_{i_{j}}}\right\}$ a subsequence of $\left\{y_{n_{i}}\right\}$ which converges weakly to $p$. Without loss of generality, we can assume that $y_{n_{i}} \rightarrow p$. Claim that

$$
p \in \cap_{i=1}^{N} \operatorname{Fix}\left(T_{i}\right) \cap \operatorname{MEP}(F, \varphi) \cap V I(C, B) .
$$

First, we prove $p \in \operatorname{MEP}(F, \varphi)$.

Since $y_{n}=T_{r_{n}} x_{n} \in \operatorname{dom} \varphi$, we have

$$
F\left(y_{n}, \eta\right)+\varphi(\eta)-\varphi\left(y_{n}\right)+\frac{1}{r_{n}}\left\langle\eta-y_{n}, y_{n}-x_{n}\right\rangle \geq 0,
$$

for all $\eta \in C$. It follows from Lemma 2.6 (A2) that

$$
\begin{gathered}
\varphi(\eta)-\varphi\left(y_{n}\right)+\frac{1}{r_{n}}\left\langle\eta-y_{n}, y_{n}-x_{n}\right\rangle \geq F\left(\eta, y_{n}\right), \\
\forall \eta \in C
\end{gathered}
$$

and hence

$$
\varphi(\eta)+\varphi\left(y_{n}\right)-\left\langle\begin{array}{c}
\left.\eta-y_{n_{i}}, \frac{y_{n_{i}}-x_{n_{i}}}{r_{n_{i}}}\right\rangle \geq F\left(\eta, y_{n_{i}}\right), \\
\forall \eta \in C .
\end{array}\right.
$$

Since $\frac{y_{n_{i}}-x_{n_{i}}}{r_{n_{i}}} \rightarrow 0$ and $y_{n_{i}} \rightarrow p$ together with the lower semicontinuity of $\varphi$ and Lemma 2.6 (A4), we have $F(\eta, p)+\varphi(p)-\varphi(\eta) \leq 0$ for all $\eta \in C$. For $t$ with $0<t \leq 1$ and $\eta \in C$, let $\eta_{t}=t \eta+(1-t) p$. Since $\eta \in C$ and $p \in C$, we have $\eta_{t} \in C$ and hence $F\left(\eta_{t}, p\right)+\varphi(p)-\varphi\left(\eta_{t}\right) \leq 0$. So, from Lemma 2.6 (A1), (A4) and the convexity of $\varphi$ we have

$$
\begin{aligned}
0= & F\left(\eta_{t}, \eta_{t}\right)+\varphi\left(\eta_{t}\right)-\varphi\left(\eta_{t}\right) \\
\leq & t F\left(\eta_{t}, \eta\right)+(1-t) F\left(\eta_{t}, p\right) \\
& +t \varphi(\eta)+(1-t) \varphi(p)-\varphi\left(\eta_{t}\right) \\
\leq & t\left(F\left(\eta_{t}, \eta\right)+\varphi(\eta)-\varphi\left(\eta_{t}\right)\right) .
\end{aligned}
$$

Dividing by $t$, we get $F\left(\eta_{t}, \eta\right)+\varphi(\eta)-\varphi(p) \geq 0$. 
Letting $t \rightarrow 0$, it follows from Lemma 2.6 (A3) and the lower semicontinuity of $\varphi$ that

$F(p, \eta)+\varphi(\eta)-\varphi(p) \geq 0$ for all $\eta \in C$ and hence $p \in \operatorname{MEP}(F, \varphi)$. Next, we prove $p \in \operatorname{Fix}(K)$. To see this, we observe that we may assume (by passing to a further subsequence if necessary) $\lambda_{n_{i}, k} \rightarrow \lambda_{k} \in(0,1)$ $(k=1,2, \cdots, N)$. Let $K$ be the $K$-mapping generated by $T_{1}, T_{2}, \cdots, T_{N}$ and $\lambda_{1}, \lambda_{2}, \cdots, \lambda_{N}$. Then by Lemma 2.5 , we have, for every $x \in C$,

$$
K_{n_{i}} x \rightarrow K x .
$$

every $x \in C$,

Moreover, from Lemma 2.4 it follows that

$$
\operatorname{Fix}(K)=\cap_{i=1}^{N} \operatorname{Fix}\left(T_{i}\right) .
$$

Suppose for contradiction $p \notin \operatorname{Fix}(K)$. Then $p \neq K p$. Since Hilbert space are Opial's spaces and

$$
p \in \operatorname{MEP}(F, \varphi)=\operatorname{Fix}\left(T_{r_{n}}\right),
$$

from (3.17) and (3.18), we have

$$
\begin{aligned}
& \liminf _{i \rightarrow \infty}\left\|z_{n_{i}}-p\right\|<\liminf _{i \rightarrow \infty}\left\|z_{n_{i}}-K p\right\| \\
& \leq \liminf _{i \rightarrow \infty}\left(\left\|z_{n_{i}}-K_{n_{i}} z_{n_{i}}\right\|+\left\|K_{n_{i}} z_{n_{i}}-K_{n_{i}} p\right\|+\left\|K_{n_{i}} p-K p\right\|\right) \\
& \leq \liminf _{i \rightarrow \infty}\left\|K_{n_{i}} Z_{n_{i}}-K_{n_{i}} p\right\| \leq \liminf _{i \rightarrow \infty}\left\|z_{n_{i}}-p\right\|,
\end{aligned}
$$

which derives a contradiction. Thus, we have $p \in \operatorname{Fix}(K)$. It follows from

$$
\operatorname{Fix}(K)=\cap_{i=1}^{N} \operatorname{Fix}\left(T_{i}\right)
$$

that

$$
p \in \cap_{i=1}^{N} \operatorname{Fix}\left(T_{i}\right) .
$$

Next, we prove $p \in \operatorname{VI}(C, B)$. Put

$$
T w_{1}= \begin{cases}B w_{1}+N_{C} w_{1}, & w_{1} \in C, \\ \varnothing, & w_{1} \notin C .\end{cases}
$$

Since $B$ is relaxed $(u, v)$-cocoercive and condition (C5), we have

$$
\begin{aligned}
\langle B x-B y, x-y\rangle & \geq(-u)\|B x-B y\|^{2}+v\|x-y\|^{2} \\
& \geq\left(v-u \mu^{2}\right)\|x-y\|^{2} \geq 0,
\end{aligned}
$$

which yields that $B$ is monotone. Thus $T$ is maximal monotone. Let $\left(w_{1}, w_{2}\right) \in G(T)$. Since $w_{2}-B w_{1} \in N_{C} w_{1}$ and $z_{n} \in C$, we have

$$
\left\langle w_{1}-z_{n}, w_{2}-B w_{1}\right\rangle \geq 0 .
$$

On the other hand, from $z_{n}=P_{C}\left(I-s_{n} B\right) y_{n}$ and (1.1), we have

$$
\left\langle w_{1}-z_{n}, z_{n}-\left(I-s_{n} B\right) y_{n}\right\rangle \geq 0
$$

and hence

$$
\left\langle w_{1}-z_{n}, \frac{z_{n}-y_{n}}{s_{n}}+B y_{n}\right\rangle \geq 0 .
$$

It follows that

$$
\begin{aligned}
\left\langle w_{1}-z_{n_{i}}, w_{2}\right\rangle \geq\left\langle w_{1}-z_{n_{i}}, B w_{1}\right\rangle & \geq\left\langle w_{1}-z_{n_{i}}, B w_{1}\right\rangle-\left\langle w_{1}-z_{n_{i}}, \frac{z_{n_{i}}-y_{n_{i}}}{s_{n_{i}}}+B y_{n_{i}}\right\rangle \\
= & \left\langle w_{1}-z_{n_{i}}, B w_{1}-B y_{n_{i}}-\frac{z_{n_{i}}-y_{n_{i}}}{s_{n_{i}}}\right\rangle \\
= & \left\langle w_{1}-z_{n_{i}}, B w_{1}-B z_{n_{i}}\right\rangle+\left\langle w_{1}-z_{n_{i}}, B z_{n_{i}}-B y_{n_{i}}\right\rangle \\
& -\left\langle w_{1}-z_{n_{i}}, \frac{z_{n_{i}}-y_{n_{i}}}{s_{n_{i}}}\right\rangle \\
\geq & \left\langle w_{1}-z_{n_{i}}, B z_{n_{i}}-B y_{n_{i}}\right\rangle-\left\langle w_{1}-z_{n_{i}}, \frac{z_{n_{i}}-y_{n_{i}}}{s_{n_{i}}}\right\rangle,
\end{aligned}
$$

which together with (3.16), (3.17) and $B$ is Lipschitz continuous implies that $\left\langle w_{1}-p, w_{2}\right\rangle \geq 0$. We have $p \in T^{-1} 0$ and hence $p \in \operatorname{VI}(C, B)$. That is,

$$
p \in \cap_{i=1}^{N} \operatorname{Fix}\left(T_{i}\right) \cap \operatorname{MEP}(F, \varphi) \cap V I(C, B) .
$$

It follows from the variational inequality $\langle(\gamma f-A) q, p-q\rangle \leq 0$ for all

$$
p \in \cap_{i=1}^{N} \operatorname{Fix}\left(T_{i}\right) \cap \operatorname{MEP}(F, \varphi) \cap V I(C, B)
$$

that

$$
\begin{aligned}
& \limsup _{n \rightarrow \infty}\left\langle(\gamma f-A) q, y_{n}-q\right\rangle \\
& =\lim _{i \rightarrow \infty}\left\langle(\gamma f-A) q, y_{n_{i}}-q\right\rangle \\
& =\langle(\gamma f-A) q, p-q\rangle \leq 0 .
\end{aligned}
$$

Using (3.16) and (3.19), we have

$$
\limsup _{n \rightarrow \infty}\left\langle(\gamma f-A) q, K_{n} z_{n}-q\right\rangle \leq 0 .
$$

Moreover, from (3.15) and (3.19), we have

$$
\limsup _{n \rightarrow \infty}\left\langle(\gamma f-A) q, x_{n}-q\right\rangle \leq 0 .
$$

Step 5. Finally, we will show that the sequences $\left\{x_{n}\right\}$ and $\left\{y_{n}\right\}$ converge strongly to $q$.

Since $z_{n}=P_{C}\left(I-s_{n} B\right) y_{n}$, using (1.19), (3.1), (3.2) and Lemma 2.8, we have 


$$
\begin{aligned}
\| & x_{n+1}-q\left\|^{2}=\right\| \alpha_{n} \gamma f\left(K_{n} x_{n}\right)+\beta_{n} x_{n}+\left(\left(1-\beta_{n}\right) I-\alpha_{n} A\right) K_{n} z_{n}-q \|^{2} \\
= & \left\|\left(\left(1-\beta_{n}\right) I-\alpha_{n} A\right)\left(K_{n} z_{n}-q\right)+\beta_{n}\left(x_{n}-q\right)+\alpha_{n}\left(\gamma f\left(K_{n} x_{n}\right)-A q\right)\right\|^{2} \\
\leq & \left\|\left(\left(1-\beta_{n}\right) I-\alpha_{n} A\right)\left(K_{n} z_{n}-q\right)+\beta_{n}\left(x_{n}-q\right)\right\|^{2}+\alpha_{n}^{2}\left\|\gamma f\left(K_{n} x_{n}\right)-A q\right\|^{2} \\
& +2 \beta_{n} \alpha_{n}\left\langle x_{n}-q, \gamma f\left(K_{n} x_{n}\right)-A q\right\rangle+2 \alpha_{n}\left\langle\left(\left(1-\beta_{n}\right) I-\alpha_{n} A\right)\left(K_{n} z_{n}-q\right), \gamma f\left(K_{n} x_{n}\right)-A q\right\rangle \\
\leq & \left(\left(1-\beta_{n}-\alpha_{n} \bar{\gamma}\right)\left\|K_{n} z_{n}-q\right\|+\beta_{n}\left\|x_{n}-q\right\|\right)^{2}+\alpha_{n}^{2}\left\|\gamma f\left(K_{n} x_{n}\right)-A q\right\|^{2}+2 \beta_{n} \gamma \alpha_{n}\left\langle x_{n}-q, f\left(K_{n} x_{n}\right)-f(q)\right\rangle \\
& +2 \beta_{n} \alpha_{n}\left\langle x_{n}-q, \gamma f(q)-A q\right\rangle+2\left(1-\beta_{n}\right) \gamma \alpha_{n}\left\langle K_{n} z_{n}-q, f\left(K_{n} x_{n}\right)-f(q)\right\rangle \\
& +2\left(1-\beta_{n}\right) \alpha_{n}\left\langle K_{n} z_{n}-q, \gamma f(q)-A q\right\rangle-2 \alpha_{n}^{2}\left\langle A\left(K_{n} z_{n}-q\right), \gamma f\left(K_{n} x_{n}\right)-A q\right\rangle \\
\leq & \left(1-\beta_{n}-\alpha_{n} \bar{\gamma}\right)^{2}\left\|K_{n} z_{n}-q\right\|^{2}+\beta_{n}^{2}\left\|x_{n}-q\right\|^{2}+2\left(1-\beta_{n}-\alpha_{n} \bar{\gamma}\right) \beta_{n}\left\|K_{n} z_{n}-q\right\|\left\|x_{n}-q\right\|+\alpha_{n}^{2}\left\|\gamma f\left(K_{n} x_{n}\right)-A q\right\|^{2} \\
& +2 \beta_{n} \gamma \alpha_{n}\left\langle x_{n}-q, f\left(K_{n} x_{n}\right)-f(q)\right\rangle+2 \beta_{n} \alpha_{n}\left\langle x_{n}-q, \gamma f(q)-A q\right\rangle+2\left(1-\beta_{n}\right) \gamma \alpha_{n}\left\langle K_{n} z_{n}-q, f\left(K_{n} x_{n}\right)-f(q)\right\rangle \\
& +2\left(1-\beta_{n}\right) \alpha_{n}\left\langle K_{n} z_{n}-q, \gamma f(q)-A q\right\rangle-2 \alpha_{n}^{2}\left\langle A\left(K_{n} z_{n}-q\right), \gamma f\left(K_{n} x_{n}\right)-A q\right\rangle \\
\leq & \left(\left(1-\beta_{n}-\alpha_{n} \bar{\gamma}\right)^{2}+\beta_{n}^{2}+2\left(1-\beta_{n}-\alpha_{n} \bar{\gamma}\right) \beta_{n}\right)\left\|x_{n}-q\right\|^{2}+\alpha_{n}^{2}\left\|\gamma f\left(K_{n} x_{n}\right)-A q\right\|^{2}+2 \beta_{n} \gamma \alpha_{n}\left\langle x_{n}-q, f\left(K_{n} x_{n}\right)-f(q)\right\rangle \\
& +2 \beta_{n} \alpha_{n}\left\langle x_{n}-q, \gamma f(q)-A q\right\rangle+2\left(1-\beta_{n}\right) \gamma \alpha_{n}\left\langle K_{n} z_{n}-q, f\left(K_{n} x_{n}\right)-f(q)\right\rangle \\
& +2\left(1-\beta_{n}\right) \alpha_{n}\left\langle K_{n} z_{n}-q, \gamma f(q)-A q\right\rangle-2 \alpha_{n}^{2}\left\langle A\left(K_{n} z_{n}-q\right), \gamma f\left(K_{n} x_{n}\right)-A q\right\rangle,
\end{aligned}
$$

which implies that

$$
\begin{aligned}
\left\|x_{n+1}-q\right\|^{2} \leq & \left(\left(1-\beta_{n}-\alpha_{n} \bar{\gamma}\right)^{2}+\beta_{n}^{2}+2\left(1-\beta_{n}-\alpha_{n} \bar{\gamma}\right) \beta_{n}+2 \gamma \alpha_{n} \alpha\right)\left\|x_{n}-q\right\|^{2}+\alpha_{n}^{2}\left\|\gamma f\left(K_{n} x_{n}\right)-A q\right\|^{2} \\
& +2 \beta_{n} \alpha_{n}\left\langle x_{n}-q, \gamma f(q)-A q\right\rangle+2\left(1-\beta_{n}\right) \alpha_{n}\left\langle K_{n} z_{n}-q, \gamma f(q)-A q\right\rangle-2 \alpha_{n}^{2}\left\langle A\left(K_{n} z_{n}-q\right), \gamma f\left(K_{n} x_{n}\right)-A q\right\rangle \\
= & \left(1-2 \alpha_{n} \bar{\gamma}+\alpha_{n}^{2} \bar{\gamma}^{2}+2 \alpha \gamma \alpha_{n}\right)\left\|x_{n}-q\right\|^{2}+\alpha_{n}^{2}\left\|\gamma f\left(K_{n} x_{n}\right)-A q\right\|^{2}+2 \beta_{n} \alpha_{n}\left\langle x_{n}-q, \gamma f(q)-A q\right\rangle \\
& +2\left(1-\beta_{n}\right) \alpha_{n}\left\langle K_{n} z_{n}-q, \gamma f(q)-A q\right\rangle-2 \alpha_{n}^{2}\left\langle A\left(K_{n} z_{n}-q\right), \gamma f\left(K_{n} x_{n}\right)-A q\right\rangle \\
\leq & \left(1-2(\bar{\gamma}-\alpha \gamma) \alpha_{n}\right)\left\|x_{n}-q\right\|^{2}+\alpha_{n}^{2} \bar{\gamma}^{2}\left\|x_{n}-q\right\|^{2}+\alpha_{n}^{2}\left\|\gamma f\left(K_{n} x_{n}\right)-A q\right\|^{2}+2 \beta_{n} \alpha_{n}\left\langle x_{n}-q, \gamma f(q)-A q\right\rangle \\
& +2\left(1-\beta_{n}\right) \alpha_{n}\left\langle K_{n} z_{n}-q, \gamma f(q)-A q\right\rangle+2 \alpha_{n}^{2}\left\|A\left(K_{n} z_{n}-q\right)\right\| \cdot\left\|\gamma f\left(K_{n} x_{n}\right)-A q\right\| \\
= & \left(1-2(\bar{\gamma}-\alpha \gamma) \alpha_{n}\right)\left\|x_{n}-q\right\|^{2}+\alpha_{n}^{2}\left(\bar{\gamma}^{2}\left\|x_{n}-q\right\|^{2}+\left\|\gamma f\left(K_{n} x_{n}\right)-A q\right\|^{2}+2\left\|A\left(K_{n} z_{n}-q\right)\right\| \cdot\left\|\gamma f\left(K_{n} x_{n}\right)-A q\right\|\right) \\
& +2 \beta_{n} \alpha_{n}\left\langle x_{n}-q, \gamma f(q)-A q\right\rangle+2\left(1-\beta_{n}\right) \alpha_{n}\left\langle K_{n} z_{n}-q, \gamma f(q)-A q\right\rangle \\
= & \left(1-2(\bar{\gamma}-\alpha \gamma) \alpha_{n}\right)\left\|x_{n}-q\right\|^{2}+\alpha_{n}\left(\alpha_{n}\left(\bar{\gamma}^{2}\left\|x_{n}-q\right\|^{2}\right)+\left\|\gamma f\left(K_{n} x_{n}\right)-A q\right\|^{2}\right. \\
& \left.+2\left\|A\left(K_{n} z_{n}-q\right)\right\| \cdot\left\|\gamma f\left(K_{n} x_{n}\right)-A q\right\|\right)+2 \beta_{n}\left\langle x_{n}-q, \gamma f(q)-A q\right\rangle+2\left(1-\beta_{n}\right)\left\langle K_{n} z_{n}-q, \gamma f(q)-A q\right\rangle .
\end{aligned}
$$

Since $\left\{x_{n}\right\},\left\{f\left(K_{n} x_{n}\right)\right\}$ and $\left\{K_{n} z_{n}\right\}$ are bounded, we can take a constant $\xi>0$ such that

$$
\begin{aligned}
\xi \geq & \bar{\gamma}^{2}\left\|x_{n}-q\right\|^{2}+\left\|\gamma f\left(K_{n} x_{n}\right)-A q\right\|^{2} \\
& +2\left\|A\left(K_{n} z_{n}-q\right)\right\| \cdot\left\|\gamma f\left(K_{n} x_{n}\right)-A q\right\|
\end{aligned}
$$

for all $n \geq 0$. It then follows that

$$
\left\|x_{n+1}-q\right\|^{2} \leq\left(1-2(\bar{\gamma}-2 \gamma) \alpha_{n}\right)\left\|x_{n}-q\right\|^{2}+\alpha_{n} \zeta_{n},
$$

where

$$
\begin{aligned}
\zeta_{n}= & 2 \beta_{n}\left\langle x_{n}-q, \gamma f(q)-A q\right\rangle \\
& +2\left(1-\beta_{n}\right)\left\langle K_{n} z_{n}-q, \gamma f(q)-A q\right\rangle+\alpha_{n} \xi .
\end{aligned}
$$

By using (3.20), (3.21) and condition (C1), we get

$$
\limsup _{n \rightarrow \infty} \zeta_{n} \leq 0 .
$$

Now applying Lemma 2.1 to (3.22) concludes that $x_{n} \rightarrow q$ as $n \rightarrow \infty$. Finally, noticing

$$
\left\|y_{n}-q\right\|=\left\|T_{r_{n}} x_{n}-T_{r_{n}} q\right\| \leq\left\|x_{n}-q\right\|
$$

we also conclude that $y_{n} \rightarrow q$ as $n \rightarrow \infty$. This completes the proof.

\section{Applications}

In this section, by Theorem 3.1, we can obtain some new 
and interesting strong convergence theorems. Now we give some examples as follows:

Let $T_{i}=I$ for all $i=1,2, \cdots, N$ and setting $\gamma=1$, $A=I$ and $f:=x$ in Theorem 3.1, we obtain the following result.

Corollary 4.1. Let $H$ be a real Hilbert space, $C$ a nonempty closed convex subset of $H, F$ a bifunction from $C \times C$ to $\mathbb{R}$ which satisfies (A1)-(A4),

$\varphi: C \rightarrow \mathbb{R} \cup\{+\infty\}$ a proper lower semicontinuous and convex function and $T_{1}, T_{2}, \cdots, T_{N}$ a finite family of nonexpansive mappings of $C$ into $H$ such that the common fixed points set $\operatorname{MEP}(F, \varphi) \cap V I(C, B) \neq \varnothing$. Assume that either (B1) or (B2) holds and $x$ is an arbitrary point in $C$. Let $\left\{x_{n}\right\}$ and $\left\{y_{n}\right\}$, be sequences generated by $x_{1} \in H$ and $\forall n \geq 1$,

$$
\left\{\begin{array}{c}
F\left(y_{n}, \eta\right)+\varphi(\eta)-\varphi\left(y_{n}\right) \\
+\frac{1}{r_{n}}\left\langle\eta-y_{n}, y_{n}-x_{n}\right\rangle \geq 0, \\
x_{n+1}=\alpha_{n} x+\beta_{n} x_{n}+\left(1-\alpha_{n}-\beta_{n}\right) P_{C}\left(I-s_{n} B\right) y_{n},
\end{array} \quad \forall \eta \in C,\right.
$$

where $\left\{\alpha_{n}\right\},\left\{\beta_{n}\right\} \subset(0,1),\left\{r_{n}\right\} \subset(0, \infty),\left\{s_{n}\right\} \subset[0, \infty)$ satisfying the conditions (C1)-(C5) in Theorem 3.1. Then, $\left\{x_{n}\right\}$ and $\left\{y_{n}\right\}$ converge strongly to a point

$$
q \in \operatorname{MEP}(F, \varphi) \cap V I(C, B),
$$

where

$$
q=P_{M E P(F, \varphi) \cap V I(C, B)}(x) .
$$

Setting $\gamma=1, \quad A=I, \quad f:=x$ and $\left\{s_{n}\right\}=0$ for all $n$ in Theorem 3.1, we obtain the following result.

Corollary 4.2. Let $H$ be a real Hilbert space, $C$ a nonempty closed convex subset of $H, F$ a bifunction from $C \times C$ to $\mathbb{R}$ which satisfies (A1)-(A4),

$\varphi: C \rightarrow \mathbb{R} \bigcup\{+\infty\}$ a proper lower semicontinuous and convex function and $T_{1}, T_{2}, \cdots, T_{N}$ a finite family of nonexpansive mappings of $C$ into $H$ such that the common fixed points set $\cap_{i=1}^{N} \operatorname{Fix}\left(T_{i}\right) \cap \operatorname{MEP}(F, \varphi) \neq \varnothing$. Let $K_{n}$ and $K$ be the $K$-mappings defined by (1.16) and (1.17), respectively. Assume that either (B1) or (B2) holds and $x$ is an arbitrary point in $C$. Let $\left\{x_{n}\right\}$ and $\left\{y_{n}\right\}$ be sequences generated by $x_{1} \in H$ and $\forall n \geq 1$,

$$
\begin{aligned}
& F\left(y_{n}, \eta\right)+\varphi(\eta)-\varphi\left(y_{n}\right)+\frac{1}{r_{n}}\left\langle\eta-y_{n}, y_{n}-x_{n}\right\rangle \geq 0, \\
& \forall \eta \in C, \\
& x_{n+1}=\alpha_{n} x+\beta_{n} x_{n}+\left(1-\alpha_{n}-\beta_{n}\right) K_{n} y_{n},
\end{aligned}
$$

where $\lambda_{1}, \lambda_{2}, \cdots, \lambda_{N}$ are real numbers such that $0<\lambda_{i}<1$ for every $i=1,2, \cdots, N-1$ and $0<\lambda_{N} \leq 1, \lambda_{n, i} \rightarrow \lambda_{i}(i=1, \cdots, N)$ and $\left\{\alpha_{n}\right\}$, $\left\{\beta_{n}\right\} \subset(0,1), \quad\left\{r_{n}\right\} \subset(0, \infty), \quad\left\{s_{n}\right\} \subset[0, \infty)$ satisfying the conditions (C1), (C3), (C4) and (C6) in Theorem 3.1. Then, $\left\{x_{n}\right\}$, and $\left\{y_{n}\right\}$ converge strongly to a point

$$
q \in \cap_{i=1}^{N} \operatorname{Fix}\left(T_{i}\right) \cap \operatorname{MEP}(F, \varphi),
$$

where

$$
q=P_{\cap_{i=1}^{N} \operatorname{Fix}\left(T_{i}\right) \cap M E P(F, \varphi)}(x) .
$$

Finally as applications, we will utilize the results presented in this paper to study the following optimization problem:

$$
\min _{\eta \in C} \varphi(\eta),
$$

where $C$ is a nonempty bounded closed convex subset of a Hilbert space and $\varphi: C \rightarrow \mathbb{R} \cup\{+\infty\}$ is a proper lower semicontinuous and convex function. We denote by $\operatorname{Argmin}(\varphi)$ the set of solutions in (4.1). Let $F(x, y)=0$ for all $x, y \in C$ in Corollary 4.1, then

$$
\operatorname{MEP}(F, \varphi)=\operatorname{Argmin}(\varphi) \text {. }
$$

It follows from Corollary 4.1 that the sequence $\left\{x_{n}\right\}$ generated by $x_{1} \in H$ and $\forall n \geq 1$,

$$
\left\{\begin{array}{l}
y_{n}=\operatorname{argmin}_{\eta \in C}\left\{\varphi(\eta)+\frac{1}{2 r_{n}}\left\|\eta-x_{n}\right\|^{2}\right\}, \\
x_{n+1}=\alpha_{n} x+\beta_{n} x_{n}+\left(1-\alpha_{n}-\beta_{n}\right) P_{C}\left(I-s_{n} B\right) y_{n},
\end{array}\right.
$$

where $\left\{\alpha_{n}\right\},\left\{\beta_{n}\right\} \subset(0,1),\left\{r_{n}\right\} \subset(0, \infty)$ and $\left\{s_{n}\right\} \subset[0, \infty)$ satisfying the conditions (C1)-(C5) in Theorem 3.1. Then the sequence $\left\{x_{n}\right\}$ converges strongly to a point

$$
q \in \operatorname{Argmin}(\varphi) \cap V I(C, B),
$$

where

$$
q=P_{\operatorname{Argmin}(\varphi) \cap V I(C, B)}(x) .
$$

Let $T_{i}=I$ for all $i=1,2, \cdots, N$ and $F(x, y)=0$ for all $x, y \in C$ in Corollary 4.2, then

$\operatorname{MEP}(F, \varphi)=\operatorname{Argmin}(\varphi)$. It follows from Corollary 4.2 that the iterative sequence $\left\{x_{n}\right\}$ generated by $x_{1} \in H$ and $\forall n \geq 1$,

$$
\left\{\begin{array}{l}
y_{n}=\operatorname{argmin}_{\eta \in C}\left\{\varphi(\eta)+\frac{1}{2 r_{n}}\left\|\eta-x_{n}\right\|^{2}\right\}, \\
x_{n+1}=\alpha_{n} x+\beta_{n} x_{n}+\left(1-\alpha_{n}-\beta_{n}\right) y_{n},
\end{array}\right.
$$

where $\left\{\alpha_{n}\right\},\left\{\beta_{n}\right\} \subset(0,1)$ and $\left\{r_{n}\right\} \subset(0, \infty)$ satisfying the conditions (C1), (C3) and (C4) in Theorem 3.1. Then the sequence $\left\{x_{n}\right\}$ converges strongly to a point $q \in \operatorname{Argmin}(\varphi)$, where $q=P_{\operatorname{Argmin}(\varphi)}(x)$.

Remark 4.3. The algorithms (4.2) and (4.3) are variants of the proximal method for optimization problems introduced and studied by Martinet [41], Rockafellar [42], Ferris [43] and many others.

\section{Acknowledgements}

This research is (partially) supported by the Centre of Excellence in Mathematics, the Commission on Higher 
Education, Thailand. The author is extremely grateful to the referees for useful suggestions that improved the contents of the paper.

\section{REFERENCES}

[1] W. Takahashi, "Nonlinear Functional Analysis: Fixed Point Theory and Its Applications," Yokohama Publishers, Yokohama, 2000.

[2] F. Deutsch and I. Yamada, "Minimizing Certain Convex Functions over the Intersection of the Fixed Point Set of Nonexpansive Mappings," Numerical Functional Analysis and Optimization, Vol. 19, No. 1-2, 1998, pp. 33-56. doi:10.1080/01630569808816813

[3] G. Marino and H. K. Xu, "A General Iterative Method for Nonexpansive Mappings in Hilbert Spaces," Journal of Mathematical Analysis and Applications, Vol. 318, No. 1, 2006, pp. 43-52. doi:10.1016/j.jmaa.2005.05.028

[4] H. K. Xu, "Iterative Algorithms for Nonlinear Operators," Journal London Mathematical Society, Vol. 66, No. 1, 2002, pp. 240-256. doi:10.1112/S0024610702003332

[5] H. K. Xu, “An Iterative Approach to Quadratic Optimization," Journal of Optimization Theory and Applications, Vol. 116, 2003, pp. 659-678. doi:10.1023/A:1023073621589

[6] I. Yamada, "The Hybrid Steepest Descent Method for the Variational Inequality Problem of the Intersection of Fixed Point Sets of Nonexpansive Mappings," In: D. Butnariu, Y. Censor and S. Reich, Eds., Inherently Parallel Algorithm for Feasibility and Optimization, Elsevier, Amsterdam, 2001, pp. 473-504. doi:10.1016/S1570-579X(01)80028-8

[7] A. Moudafi, "Viscosity Approximation Methods for Fixed Points Problems," Journal of Mathematical Analysis and Applications, Vol. 241, No. 1, 2000, pp. 46-55. doi:10.1006/jmaa.1999.6615

[8] R. U. Verma, "Generalized System for Relaxed Cocoercive Variational Inequalities and Its Projection Methods," Journal of Optimization Theory and Applications, Vol. 121, No. 1, 2004, pp. 203-210. doi:10.1023/B:JOTA.0000026271.19947.05

[9] R. U. Verma, "General Convergence Analysis for TwoStep Projection Methods and Application to Variational Problems," Applied Mathematics Letters, Vol. 18, No. 2, 2005, pp. 1286-1292. doi:10.1016/j.aml.2005.02.026

[10] R. U. Verma, "Sensitivity Analysis for Relaxed Cocoercive Nonlinear Quasivariational Inclusions," Journal of Applied Mathematics and Stochastic Analysis, No. 3, 2006, pp. 1-10. doi:10.1155/JAMSA/2006/52041

[11] W. Takahashi and M. Toyoda, "Weak Convergence Theorems for Nonexpansive Mappings and Monotone Mappings," Journal of Optimization Theory and Applications, Vol. 118, No. 2, 2003, pp. 417-428. doi:10.1023/A:1025407607560

[12] H. Iiduka and W. Takahashi, "Strong Convergence Theorems for Nonexpansive Mappings and Inverse-Strongly Monotone Mappings," Nonlinear Analysis, Vol. 61, No. 4, 2005, pp. 341-350. doi:10.1016/j.na.2003.07.023
[13] X. Qin, S. M. Kang and M. Shang, "Strong Convergence Theorems of k-Strict Pseudo-Contractions in Hilbert Spaces," Czechoslovak Mathematical Journal, Vol. 59, No. 3, 2009, pp. 695-706. doi:10.1007/s10587-009-0041-3

[14] L. C. Ceng and J. C. Yao, "A Hybrid Iterative Scheme for Mixed Equilibrium Problems and Fixed Point Problems," Journal of Computational and Applied Mathematics, Vol. 214, No. 1, 2008, pp. 186-201. doi:10.1016/j.cam.2007.02.022

[15] P. L. Combettes and S. A. Hirstoaga, "Equilibrium Programming in Hilbert Spaces," Journal of Nonlinear and Convex Analysis, Vol. 6, No. 1, 2005, pp. 117-136.

[16] S. D. Flam and A. S. Antipin, "Equilibrium Programming Using Proximal-Like Algorithms," Mathematical Programming, Vol. 78, No. 1, 1997, pp. 29-41. doi:10.1007/BF02614504

[17] E. Blum and W. Oettli, "From Optimization and Variational Inequalities to Equilibrium Problems," Mathematics Student-India, Vol. 63, No. 1-4, 1994, pp. 123-145.

[18] J. W. Peng and J. C. Yao, "A New Hybrid-Extragradient Method for Generalized Mixed Equilibrium Problems and Fixed Point Problems and Variational Inequality Problems," Taiwanese Journal of Mathematics, Vol. 12, No. 6, 2008, pp. 1401-1432.

[19] J. W. Peng and J. C. Yao, "Strong Convergence Theorems of Iterative Scheme Based on the Extragradient Method for Mixed Equilibrium Problems and Fixed Point Problems," Mathematical and Computer Modelling, Vol. 49, No. 9-10, 2009, pp. 1816-1828. doi:10.1016/j.mcm.2008.11.014

[20] S. Takahashi and W. Takahashi, "Viscosity Approximation Methods for Equilibrium Problems and Fixed Point Problems in Hilbert Spaces," Journal of Mathematical Analysis and Applications, Vol. 331, No. 1, 2007, pp. 506515. doi:10.1016/j.jmaa.2006.08.036

[21] M. Shang, Y. Su and X. Qin, “A General Iterative Method for Equilibrium Problems and Fixed Point Problems in Hilbert Spaces," Fixed Point Theory and Applications, 2007, Article ID: 95412.

[22] H. H. Bauschke, "The Approximation of Fixed Points of Compositions of Nonexpansive Mappings in Hilbert Space," Journal of Mathematical Analysis and Applications, Vol. 202, No. 1, 1996, pp. 150-159. doi:10.1006/jmaa.1996.0308

[23] H. H. Bauschke and J. M. Borwein, "On Projection Algorithms for Solving Convex Feasibility Problems," SIAM: SIAM Review, Vol. 38, No. 3, 1996, pp. 367-426. doi:10.1137/S0036144593251710

[24] P. L. Combettes, "Constrained Image Recovery in a Product Space," Proceedings of the IEEE International Conference on Image Processing, Washington DC, 23-26 October 1995, pp. 2025-2028. doi:10.1109/ICIP.1995.537406

[25] P. L. Combettes, "The Foundations of Set Theoretic Estimation," Proceeding of the IEEE, Vol. 81, No. 2, 1993, 182-208. doi:10.1109/5.214546

[26] F. Deutsch and H. Hundal, "The Rate of Convergence of 
Dykstra's Cyclic Projections Algorithm: The Polyhedral Case," Numerical Functional Analysis and Optimization, Vol. 15, No. 5-6, 1994, pp. 537-565. doi:10.1080/01630569408816580

[27] D. C. Youla, "Mathematical Theory of Image Restoration by the Method of Convex Projections," In: H. Stark, Ed., Image Recovery: Theory and Applications, Academic Press, Gainesville, 1987, pp. 29-77.

[28] I. Yamada and N. Ogura, "Hybrid Steepest Descent Method for the Variational Inequality Problem over the Fixed Point Set of Certain Quasi Nonexpansive Mappings," Numerical Functional Analysis and Optimization, Vol. 25, No. 7-8, 2004, pp. 619-655. doi:10.1081/NFA-200045815

[29] S. Atsushiba and W. Takahashi, "Strong Convergence Theorems for a Finite Family of Nonexpansive Mappings and Applications," Indian Journal of Mathematics, Vol. 41, No. 3, 1999, pp. 435-453.

[30] G. Emmanuele, "A Remark on a Paper: Common Fixed Points of Nonexpansive Mappings by Iteration by P. K. F. Kuhfittig," Pacific Journal of Mathematics, Vol. 110, No. 2, 1984, pp. 283-285. doi:10.2140/pjm.1984.110.283

[31] P. K. F. Kuhfittig, "Common Fixed Points of Nonexpansive Mappings by Iteration," Pacific Journal of Mathematics, Vol. 97, No. 1, 1981, pp. 137-139. doi:10.2140/pjm.1981.97.137

[32] W. Takahashi, "Weak and Strong Convergence Theorems for Families of Nonexpansive Mappings and Their Applications," Annales Universitatis Mariae Curie-Sklodowska, Vol. 51, 1997, pp. 277-292.

[33] W. Takahashi and K. Shimoji, "Convergence Theorems for Nonexpansive Mappings and Feasibility Problems," Mathematical and Compute Modelling, Vol. 32, No. 11, 2000, pp. 1463-1471. doi:10.1016/S0895-7177(00)00218-1

[34] X. Qin, M. Shang and Y. Su, "Strong Convergence of a General Iterative Algorithm for Equilibrium Problems and Variational Inequality Problems," Mathematical and Compute Modelling, Vol. 48, No. 7-8, 2008, pp. 1033-1046. doi:10.1016/j.mcm.2007.12.008

[35] V. Colao, G. Marino and H. K. Xu, "An Iterative Method for Finding Common Solutions of Equilibrium and Fixed Point Problems," Journal of Mathematical Analysis and Applications, Vol. 344, No. 1, 2008, pp. 340-352. doi:10.1016/j.jmaa.2008.02.041

[36] Y. Yao, M. A. Noor and Y. C. Liouc, "On Iterative Methods for Equilibrium Problems," Nonlinear Analysis, Vol. 70, No. 9, 2009, pp. 497-509. doi:10.1016/j.na.2007.12.021

[37] A. Kangtunyakarn and S. Suantai, "A New Mapping for Finding Common Solutions of Equilibrium Problems and Fixed Point Problems of Finite Family of Nonexpansive Mappings," Nonlinear Analysis, Vol. 71, No. 10, 2009 pp. 4448-4460. doi:10.1016/j.na.2009.03.003

[38] Z. Opial, "Weak Convergence of Successive Approximations for Nonexpansive Mappins," Bulletin of the American Mathematical Society, Vol. 73, No. 4, 1967, pp. 591597. doi:10.1090/S0002-9904-1967-11761-0

[39] R. T. Rockafellar, "On the Maximality of Sums of Nonlinear Monotone Operators," Transactions of the American Mathematical Society, Vol. 149, No. 1, 1970, pp. 75-88. doi:10.1090/S0002-9947-1970-0282272-5

[40] T. Suzuki, "Strong Convergence of Krasnoselskii and Mann's Type Sequences for One-Parameter Nonexpansive Semigroups without Bochner Integrals," Journal of Mathematical Analysis and Applications, Vol. 305, No. 1, 2005, pp. 227-239. doi:10.1016/j.jmaa.2004.11.017

[41] B. Martinet, "Perturbation Des Méthodes d'Optimisation," AIRO Analyse Numérique, Vol. 12, No. 2, 1978, pp. 153-171.

[42] R. T. Rockafellar, "Monotone Operators and the Proximal Point Algorithm," IAM: SIAM Journal on Control and Optimization, Vol. 14, No. 5, 1976, pp. 877-898. doi: $10.1137 / 0314056$

[43] M. C. Ferris, "Finite Termination of the Proximal Point Algorithm," Mathematical Programming, Vol. 50, No. 1-3, 1991, pp. 359-366. doi:10.1007/BF01594944 